Cahiers du MONDE RUSSE

\section{Cahiers du monde russe}

Russie - Empire russe - Union soviétique et États indépendants

$56 / 4 \mid 2015$

Médiateurs d'empire en Asie centrale (1820-1928)

\title{
Le ralliement des Kazakhs au pouvoir soviétique (1917-1920)
}

Convictions politiques, système tribal et contexte russe*

Kazakh rallying to Soviet power (1917-1920): Political convictions, tribal system, and Russian context

\section{Xavier Hallez}

\section{OpenEdition}

Journals

Édition électronique

URL : http://journals.openedition.org/monderusse/8218

DOI : $10.4000 /$ monderusse. 8218

ISSN : $1777-5388$

Éditeur

Éditions de l'EHESS

Édition imprimée

Date de publication : 1 octobre 2015

Pagination : 705-752

ISBN : 978-2-7132-2507-9

ISSN : $1252-6576$

\section{Référence électronique}

Xavier Hallez, «Le ralliement des Kazakhs au pouvoir soviétique (1917-1920) », Cahiers du monde russe [En ligne], 56/4 | 2015, mis en ligne le 01 octobre 2018, Consulté le 02 mai 2019. URL : http:// journals.openedition.org/monderusse/8218; DOI : 10.4000/monderusse.8218

Ce document a été généré automatiquement le 2 mai 2019.

(c) École des hautes études en sciences sociales 


\title{
Le ralliement des Kazakhs au pouvoir soviétique (1917-1920)
}

\author{
Convictions politiques, système tribal et contexte russe* \\ Kazakh rallying to Soviet power (1917-1920): Political convictions, tribal system, \\ and Russian context
}

Xavier Hallez

*Dans cet article, la translittération des caractères de l'alphabet kazakh cyrillique se fonde sur les normes suivies dans les Cahiers d'Asie centrale $:$ http://asiecentrale.revues.org/2749?file=1

1 À la veille des révolutions de 1917, on ne recense qu'un seul bolchevik kazakh, avant que leur nombre ne s'élève à 1588 en $1921^{1}$. De même, le Parti socialiste révolutionnaire ne compte qu'un seul membre kazakh ${ }^{2}$. Aucun des deux n'a été un militant actif. Avant 1917, et bien qu'elle n'ait pas été non plus imperméable aux idées révolutionnaires diffusées dans tout l'Empire russe, la société kazakhe n'a pas connu de développement de groupes révolutionnaires ou de partis socialistes. Dès lors, on peut s'interroger sur les événements révolutionnaires survenus dans les steppes kazakhes: qui étaient ces Kazakhs qui furent associés aux soviets et devinrent communistes, quelles étaient leurs motivations? Cet article se penche sur des parcours individuels et différentes formes de l'engagement politique dans la société kazakhe durant la période 1917-1920. Il trouve sa place à la suite de publications plus générales sur l'histoire du discours national kazakh et de la construction de la république autonome kazakhe ${ }^{3}$.

2 Malgré une abondante historiographie soviétique sur les mouvements révolutionnaires dans les steppes kazakhes, le sujet a surtout été traité au travers de la constitution des organes locaux du pouvoir soviétique ou de l'activité du parti communiste ${ }^{4}$. L'engagement des Kazakhs dans la cause révolutionnaire et leur adhésion au projet bolchevik ou soviétique ont été abordés selon un schéma idéologique uniforme: origine plébéienne souvent fictive, confrontation aux inégalités sociales dans la société kazakhe et au sein de l'Empire russe, influence de révolutionnaires russes et rejet de la politique menée par le Gouvernement provisoire russe entre février et octobre 1917. La seule approche portant sur les idées défendues par les Kazakhs se borne à décrire les lignes respectives des deux 
journaux Ajqap (1911-1915) et Qazaq (1913-1918) - le premier présenté comme progressiste, le second comme " conservateur-bourgeois " ou "nationaliste-bourgeois " -, et ce qui les oppose. Après 1991, les publications kazakh-stanaises se sont détournées de cette histoire de la révolution pour se concentrer sur la fabrique d'un mouvement national, dénommé la rébellion ou le mouvement Alaš (Alaš qozghalysy en kazakh et Dviženie Alaš en russe). La diversité politique y est minorée au profit d'une présentation de l'unité des Kazakhs derrière le projet d'une autonomie nationale et l'activité du Conseil national Alaš orda entre 1917 et 1920. Les rares publications en dehors de l'espace postsoviétique sur cette période de l'histoire des Kazakhs sont consacrées soit aux événements révolutionnaires au Turkestan, soit à Alaš orda ${ }^{6}$.

3 Un article de Tomohiko Uyama ${ }^{7}$ ouvre une nouvelle perspective: la géographie et l'appartenance tribale des acteurs kazakhs y sont introduites dans l'analyse des choix politiques. Cette présente étude la prolonge et complète un article précédent consacré aux mouvements politiques kazakhs entre 1905 et $1918^{8}$. Elle cherche à comprendre comment s'est articulé le mode d'organisation politique kazakh associé au système tribal et comment il s'est superposé à celui importé de Russie. Durant la période révolutionnaire, le modèle russe s'est exprimé dans l'organisation de congrès régionaux et pankazakhs, dans la création de partis politiques et dans les formes de la représentation par rapport à un centre russe. Nous nous proposons de déterminer l'impact de l'appartenance tribale et lignagère dans les choix politiques et l'évolution des modalités du politique dans la société kazakhe au cours de cette même période.

L'une des difficultés rencontrées dans la construction des faits nécessaires à une telle étude a résidé dans la détermination de l'appartenance tribale des acteurs, car l'idéologie soviétique, puis le mythe de l'unité kazakhe ont eu pour effet de l'effacer ou de l'omettre. Les récentes publications généalogiques au Kazakhstan ont été précieuses pour l'établir 9 . Par ailleurs, à l'exception de conflits locaux lors des élections des gouverneurs de volost' [district] et de rares rapports de police, le rôle des relations tribales reste très largement en dehors des archives tsaristes. Cette absence est encore plus significative pour la période étudiée. Les comptes rendus des congrès kazakhs des années 1917-1918 et la presse kazakhe n'y font qu'allusion et seuls quelques témoignages apportent des éléments concrets. La construction nationale du début du xx ${ }^{\mathrm{e}}$ siècle s'accompagna d'un discours sur la nécessaire mise en retrait des tribus dans la vie politique. Ainsi le jeu des tribus fut sous-jacent sans que les acteurs ne le mentionnent explicitement hormis dans des situations particulières.

5 Les tribus kazakhes sont réparties entre trois žüz [hordes], la žüz aînée, la žüz moyenne et la žüz cadette, qui occupent chacune des zones géographiques distinctes respectivement au sud, au centre et à l'est, et à l'ouest de l'actuel Kazakhstan ${ }^{10}$. Elles sont elles-mêmes divisées en grandes unités lignagères qui se segmentent à leur tour, l'unité sociale étant le lignage. Le lignage « consists of all the descendants in one line of a particular person through a determinate number of generations $»^{11}$.

6 À la période étudiée, comme le souligne Nurbulat Masanov, la structure tribale restait au fondement de l'organisation politique des Kazakhs :

La filiation individuelle n'était qu'un cas particulier dans la structure généalogique de la parenté par rapport à la filiation du groupe, en dehors duquel aucun individu n'existait et ne pouvait concevoir son existence sociale. ${ }^{12}$ 
7 Un des principaux recueils sur le droit coutumier kazakh note qu' « un individu, exclu de sa communauté tribale et privé de son soutien, n'a plus aucun droit parmi les Kirghiz (Kazakhs) $»^{13}$. Masanov d'ajouter :

L'importance du système de parenté était particulièrement grande dans la sphère des représentations, de l'idéologie et de la répartition des fonctions du pouvoir. ${ }^{14}$

Il était ainsi particulièrement difficile pour un Kazakh de se désolidariser de son lignage et de sa tribu et de ne pas respecter la parole des aînés.

9 Les élites tribales commandaient les décisions politiques des tribus et des lignages et élisaient les khans, issus d'un groupe particulier, les töre, descendants de khans kazakhs et tirant leur légitimité d'une filiation gengiskhanide. Officiellement, le titre de khan fut aboli par le régime tsariste dans la première moitié $d u \mathrm{xIX}^{\mathrm{e}}$ siècle, mais les tribus continuèrent à élire leur khan lors des rébellions contre le pouvoir russe. Même si elle ne se traduisit plus nécessairement par une domination des gengiskhanides dans les institutions administratives coloniales et qu'elle put être contestée, la préséance politique des töre perdura ${ }^{15}$.

10 L'intégration dans l'Empire russe avait fait évoluer le fonctionnement politique des tribus et des lignages, sans leur retirer leur rôle central. Le statut d'allogène, auquel étaient soumis les Kazakhs, préservait l'organisation autochtone au niveau local. Le pouvoir russe chercha à éclater les tribus pour les affaiblir sans pour autant proposer une recomposition politique alternative. La représentation de la population kazakhe fut limitée à l'élection de gouverneurs de volost et toute expression nationale fut combattue par les autorités tsaristes. Le pouvoir russe scinda les Kazakhs entre plusieurs entités administratives : la Horde intérieure ou Horde de Bukej intégrée dans la gubernija [région] d'Astrahan', les oblasts [régions] d'Ural'sk et de Turgaj, le Gouvernorat général des steppes, qui comprenait les oblasts de Semipalatinsk et d'Akmolinsk, et le Gouvernorat général du Turkestan. Le présent article ne prend pas en considération la situation au Turkestan, qui n'a pas été associé à la constitution des organes soviétiques et communistes kazakhs durant la période étudiée. La žüz aînée est donc absente de cette étude ${ }^{16}$.

$11 \mathrm{Au}$ début du Xx $\mathrm{x}^{\mathrm{e}}$ siècle, le nombre croissant de Kazakhs intégrant un cursus scolaire russe modifia le paysage politique kazakh. Ces intelligenty, comme on les nommait, entrèrent majoritairement au service de l'État russe, en tant qu'interprètes, instituteurs, médecins, vétérinaires, agronomes, personnels administratifs ou de justice. Ils devinrent les intermédiaires entre les autorités tsaristes et la population kazakhe, tout en aspirant à aider à la transformation de la société kazakhe. Leurs ambitions personnelles - élévation sociale et accès à un mode de vie différent - allaient de pair avec leur dévouement à la cause de leurs compatriotes. La révolution de 1905, puis l'apparition d'une presse kazakhe à partir de 1907 en firent les porte-parole des revendications kazakhes devant le pouvoir russe. La pression coloniale avait plongé la population nomade dans une situation de crise économique et sociale, dont l'issue devait s'incarner, selon l'intelligentsia, dans la modernisation de la société et des modalités du politique. Au-delà des divergences, le projet d'une unité nationale des Kazakhs s'imposa et les divisions tribales furent perçues comme un frein à sa réalisation. Ce projet était aussi largement partagé par le milieu religieux kazakh impliqué dans la diffusion du réformisme musulman ou djadidisme.

12 Les étudiants, les employés et les fonctionnaires kazakhs, venus de différents oblasts avaient pu créer une nouvelle sociabilité dans les principales villes à la périphérie des 
steppes (Orenburg, Omsk, Ural'sk,...). Toutefois, ce milieu restait très minoritaire au sein de la société kazakhe, dont la vie politique était toujours régie par le système tribal et rythmée par les élections des gouverneurs de volost. Les seules élections « régionales" avant 1917 furent celles des deux Premières Dumas d'État en 1906 et 1907 et le choix des candidats fut décidé par les assemblées des tribus au niveau des oblasts ${ }^{17}$. Au-delà de la diffusion de nouvelles idées et du projet national, l'influence politique des intelligenty passait par la mobilisation des solidarités tribales et par leur dépendance à un pouvoir russe.

13 Six situations se dégagent de l'analyse des parcours des Kazakhs ayant rallié les soviets et le parti bolchevik : la première, qui se reflète dans le cas isolé d'Alibi Džangil'din ${ }^{18}$, le seul bolchevik kazakh avant la révolution de 1917, est celle d'un positionnement politique antérieur au sein d'une organisation révolutionnaire. La deuxième se caractérise par une action politique marquée par l'affrontement ou le contournement du pouvoir, représentée par la figure du «bandit social ${ }^{19}$, batyr ${ }^{20}$ ou barymtašy ${ }^{21}$ dans le contexte kazakh, et incarnée par Amangel'dy Imanov. La troisième se rapporte à un processus commun à l'ensemble de la Russie et s'exprime dans la radicalisation progressive au cours de l'année 1917 qui fut très présente chez les jeunes générations. La quatrième se distingue du cas russe et s'ancre à la fois dans le fonctionnement du politique chez les Kazakhs et dans la constitution d'un mouvement national: les personnalités mises à l'écart de la représentation nationale ont trouvé dans la montée d'un nouveau pouvoir, celui des soviets, la possibilité d'entrer à nouveau dans le jeu politique. La cinquième, qui peut parfois se confondre avec la précédente, rassemble les acteurs kazakhs qui ont fait le pari de croire aux intentions du pouvoir soviétique et des bolcheviks de prendre en compte les intérêts des populations non-russes. Elle fut souvent assimilée au refus de collaborer avec des gouvernements russes associés à l'ancien régime tsariste ou jugés contre-révolutionnaires et avec ceux rejetant le principe des autonomies nationales. La sixième est difficile à distinguer du pari, car elle repose sur une stratégie proche de l'entrisme et consiste à placer ses partisans dans des organisations ennemies pour anticiper une éventuelle victoire de ces dernières.

L'articulation de cette typologie, somme toute théorique, apporte un éclairage sur les convictions politiques des protagonistes que les sources explicitent rarement. Les Mémoires, les récits autobiographiques ou les biographies des communistes kazakhs proposent une vision trop linéaire de l'engagement politique et reposent souvent sur des faits erronés. Nombre de journaux tirés à petits tirages et de tracts contemporains de la période révolutionnaire ont disparu. Peu de discours de Kazakhs ayant rallié les soviets ou le parti bolchevik ont été retranscrits. Il convient ainsi de tenter de recomposer une pensée politique à partir de sources parcellaires et multiples, sans oublier qu'aucun des acteurs étudiés ne resta figé sur ses positions. La période révolutionnaire bouleversa les projets politiques qui évoluèrent sans cesse suivant un contexte politique bouillonnant.

À la différence du mouvement national kazakh, qui s'organisa au travers de congrès et de divers comités, les groupes engagés dans les soviets ou au parti bolchevik étaient dispersés entre les différents oblasts et aucun congrès pankazakh soviétique ne fut réuni avant octobre 1920. Les organes soviétiques kazakhs constitués entre 1918 et 1919 agglomérèrent lentement ces groupes dont nous allons présenter la diversité. Chaque oblast offrait en effet un visage différent et les six situations décrites précédemment s'y manifestèrent de manière disparate. 
La période 1917-1920 est découpée en cinq phases, correspondant à des étapes significatives dans le choix du ralliement ou non des Kazakhs au pouvoir soviétique. Dans les premières phases, le cas de chaque oblast (Turgaj, Ural'sk, Bukej, Akmolinsk et Semipalatinsk) sera présenté de manière séparée, avant que les différents groupes n'interagissent.

Le Kazakhstan à la fin de la période tsariste

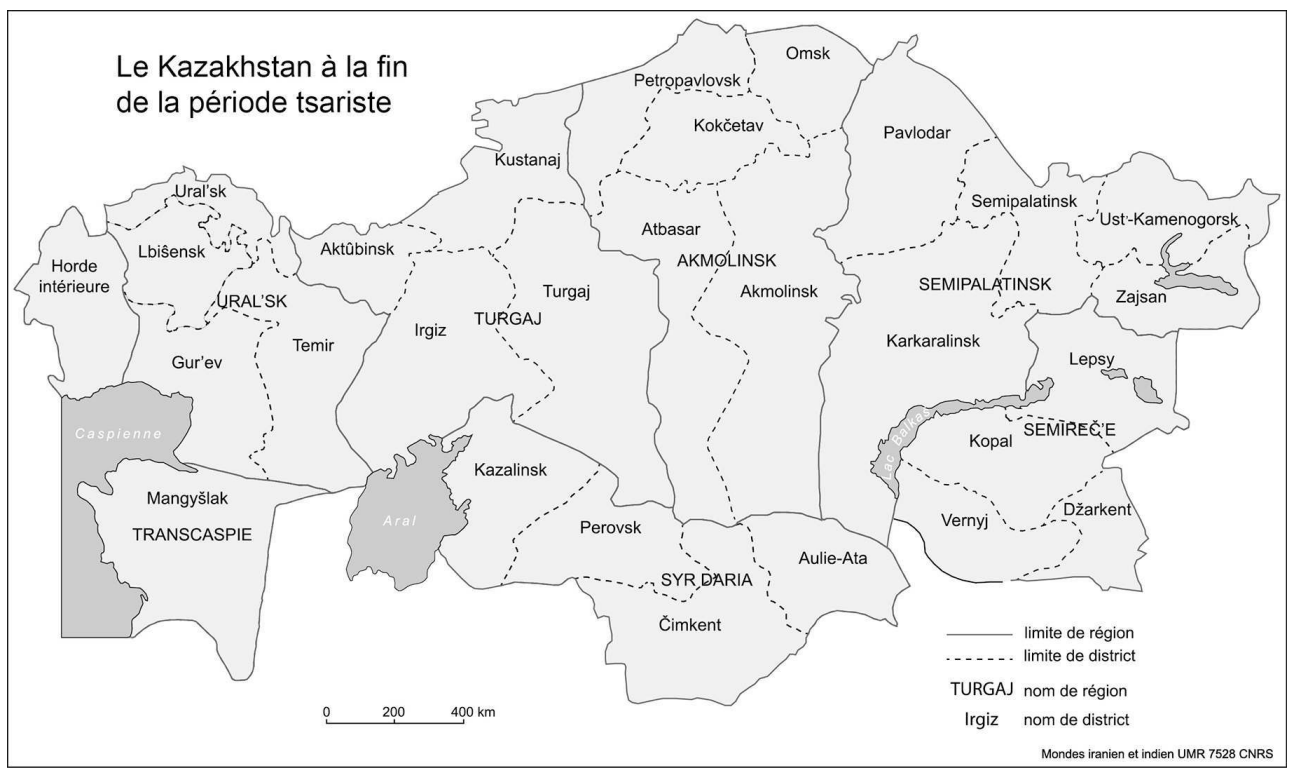

Crédit : Mondes iranien et indiens UMR7528 CNRS

\section{Première phase : la révolution de février 1917 et l'effervescence politique dans les steppes}

\section{L'oblast de Turgaj}

À l'aube de la révolution de 1917, le contexte politique de cette région était particulièrement complexe. L'oblast de Turgaj était la seule des cinq régions septentrionales à comprendre des tribus appartenant à deux žüz distinctes. Les uezdy [départements] de Turgaj et de Kustanaj étaient peuplés essentiellement de membres des tribus qypšaq et arghyn de la žüz moyenne et ceux d'Aktjubinsk et d'Irgiz de membres des tribus žetìru et älìmuly de la žüz cadette. La ville d'Orenburg, centre administratif de l'oblast et important nœud ferroviaire, abritait un des groupes les plus actifs et les plus influents de l'intelligentsia kazakhe, autour d'Alihan Bukejhanov, Ahmet Bajtursunov et Miržakup Dulatov. Ces deux derniers étaient les rédacteurs en chef de Qazaq, seul organe de presse kazakh diffusé dans toutes les steppes entre 1915 et $1918^{22}$. Enfin, la rébellion, qui avait éclaté dans toute l'Asie centrale contre le décret de mobilisation de juin 1916, restait active seulement dans l'uezd de Turgaj.

Après février 1917, le Gouvernement provisoire russe nomma au poste de commissaire de l'oblast Alihan Bukejhanov, qui assura la relève de l'administration tsariste et put placer des Kazakhs à la tête de presque tous les uezds ${ }^{23}$. Bukej-hanov, d'origine töre, était le leader reconnu de l'intelligentsia kazakhe avant 1917 et fut élu député à la Première 
Duma d'État grâce au soutien de la tribu arghyn dans l'oblast de Semipalatinsk ${ }^{24}$. Il était aussi parfaitement intégré dans les milieux intellectuels et politiques libéraux russes. En position de force après sa nomination, il organisa le premier congrès régional kazakh à Orenburg, puis les deux congrès pankazakhs s'y déroulèrent en juillet et novembre 1917. Cette ville devint ainsi le cœur du mouvement national kazakh, avant de devenir la première capitale de la République autonome soviétique kazakhe en 1920.

Le seul bolchevik recensé avant 1917, Alibi Džangil'din, était lui-aussi originaire de cet oblast et devint la figure centrale de la construction des organes soviétiques kazakhs. Sa biographie présente de nombreuses zones d'ombre, que l'historiographie a réécrites à l'aune de son propre récit autobiographique et des besoins de la propagande soviétique. Alibi Džangil'din naquit en 1884 dans un volost qypšaq de l'uezd de Turgaj, dont était aussi natif son aîné Amangel'dy Imanov, autre héros du panthéon soviétique kazakh. Son parcours scolaire et professionnel fut chaotique. Après des études inachevées, il fut engagé en 1904 comme interprète dans l'administration régionale ${ }^{25}$. Il avait été introduit par Bajkadam Karaldin, intelligent originaire d'un volost qypšaq voisin du sien et employé de l'administration de l'uezd depuis 1892. Karaldin joua un rôle important pour les Kazakhs de sa région. Outre ses conseils et son aide dans les démarches administratives, il s'efforça d'apaiser les relations entre les autorités russes et ses compatriotes. Maniant l'art du compromis, il suivit toujours une ligne modérée. Il s'attacha aussi à favoriser la sédentarisation des Kazakhs et le développement de l'agriculture, perçus comme des vecteurs de la modernité26.

Džangil'din ne se contenta pas de cet emploi et décida de partir pour Moscou. Il baigna dans la vie moscovite tumultueuse et collabora à quelques journaux. Très certainement fasciné par les voyageurs étrangers de passage en Russie, il décida de suivre leur exemple et publia une annonce pour trouver des compagnons de route à son projet de tour du monde à pied. Deux Russes se manifestèrent à lui et ils partirent en 1908 pour l'Europe de l'Est. Comme il le raconte, il prit la route «avec de solides souliers aux pieds, une veste courte sur le dos, une coiffe caucasienne en feutre sur la tête, 25 roubles et un appareil photo en poche $\|^{27}$. Son départ n'était pas motivé par le désir d'intégrer un circuit révolutionnaire, tel que cela fut le cas pour de nombreux militants anticoloniaux entre la fin du XIX et le début du xx $x^{e}$ siècle $^{28}$. Il était davantage question d'un parcours spirituel et intellectuel personnel. Il finança son voyage en vendant ses photographies prises dans les pays visités, puis en projetant des films qu'il tourna. Ses compagnons de route l'abandonnèrent en Hongrie et il continua seul ses pérégrinations. Après avoir visité l'Europe de l'Est, il se rendit dans l'Empire ottoman et découvrit Jérusalem, puis les Lieux saints de l'islam, Médine et La Mecque. Il prolongea son voyage par l'Inde, l'Asie du Sud-Est et s'arrêta au Japon. Pour son retour, il prit le bateau jusqu'au port de Vladivostok, puis traversa la Sibérie pour retrouver sa terre natale après trois ans de voyage.

21 Il s'installa dans la ville de Turgaj et y fréquenta la bonne société provinciale. Le récit de ses voyages lui servit d'introduction. Il rencontra ainsi sa première femme, Rail' Turshu, la fille d'un important marchand karaïme ${ }^{29}$ de Crimée, qui travaillait comme médecin à Turgaj $^{30}$. L'historiographie affirme qu'Alibi aurait été inquiété par les autorités tsaristes locales et aurait dû se cacher avant de décider de partir pour la Crimée. Aucun document ne permet pour l'instant de déterminer les réelles motivations de son installation en Crimée. À son arrivée, il trouva une place à l'observatoire de Pulkovo, où il fut chargé des 
observations météorologiques. Il fut accueilli par son influente belle-famille et se mêla à la vie sociale et politique criméenne.

Les idéaux socialistes et révolutionnaires inspiraient la majeure partie de la jeunesse éduquée en Russie pour laquelle l'enjeu était de situer son positionnement politique, modéré ou radical, et de décider ou non de s'impliquer dans des mouvements ou des partis. La famille de Rail' Turshu était progressiste. Une de ses sœurs, Beruha, membre d'un parti révolutionnaire, fut arrêtée et décéda en prison. Rail' et une autre de ses sœurs étaient de même sensibilité politique, sans pour autant s'engager dans une réelle activité militante. Džangil'din décida au contraire de s'impliquer et se rapprocha du milieu bolchevik. Selon son propre témoignage, il se rendit à Petrograd en 1915 avec un certain Ivanov, bolchevik travaillant à l'administration de la gubernija de Simferopol et reçut sa carte de membre du parti ${ }^{31}$. Dans son autobiographie, Džangil'din demeure elliptique sur ses convictions politiques et les raisons de son adhésion.

Sa vie bascula par suite d'une lettre d'Amangel'dy Imanov qu'il reçut au début de l'été 1916. Le décret de mobilisation des allogènes pour les travaux auxiliaires avait été publié le 25 juin, alors que les allogènes avaient toujours été exemptés de service militaire. La population kazakhe était très inquiète et la majorité peu encline à voir partir les futurs conscrits loin de leur terre pour participer à un conflit éloigné de leurs préoccupations. La brutalité et l'impréparation de la mobilisation provoquèrent des réactions de plus en plus violentes. Alors que la rébellion n'en était qu'à ses prémisses, Imanov enjoignit à Džangil'din de revenir. Ce dernier s'empressa de quitter la Crimée pour retrouver les siens et participer à ce mouvement.

Imanov, descendant d'Iman batyr ${ }^{32}$, un des proches lieutenants de Kenesary Kasymov ${ }^{33}$, était une figure incontournable de l'uezd de Turgaj et sa renommée s'étendait à tout

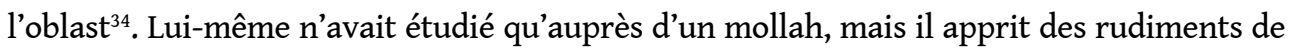
russe et ouvrit une école dans son aul [village]. Favorable à la sédentarisation, il promut la construction de canaux d'irrigation dans son volost. Connu comme barymtašy, Imanov s'illustra par ses actions contre le pouvoir russe et par ses activités politiques (en particulier lors des élections du gouverneur de volost). Arrêté à plusieurs reprises, il parvint à échapper à la déportation grâce au soutien des siens et de certains fonctionnaires kazakhs comme Karaldin. Toujours accompagné de džigit ${ }^{35}$ qypšaq, il pouvait se permettre de s'opposer aux décisions des gouverneurs de volost et refuser de se soumettre à l'arbitraire de l'autorité locale russe. Afin d'affirmer son statut de batyr, il abandonna son patronyme d'Uderbaev pour celui d'Imanov en l'honneur de son illustre ancêtre. Il soignait son image de justicier en faveur des lignages les plus faibles et de défenseur des Kazakhs face à l'administration coloniale. Les nombreuses légendes à son sujet transmises oralement en témoignent ${ }^{36}$.

25 Si la rébellion se déclencha durant l'été au Turkestan pour se terminer au mois de septembre après une féroce répression, la chronologie fut très différente plus au nord et notamment dans l'oblast de Turgaj, où se trouvait le principal foyer septentrional de la rébellion ${ }^{37}$. La mobilisation s'effectua sans heurts majeurs en septembre 1916 dans les uezds d'Aktjubinsk et de Kustanaj. Les élites tribales et les intelligenty parvinrent à y apaiser la révolte naissante contre le décret. En revanche, lors des journées prévues pour la mobilisation en octobre dans les deux autres uezds de l'oblast, les jeunes Kazakhs ne se présentèrent pas. Au contraire, des attaques menées par des barymtašy furent lancées contre les positions russes. Imanov, à la tête de plusieurs milliers d'hommes, lança des raids et assiégea la ville de Turgaj pendant deux mois. Dans l'uezd de Turgaj, la rébellion 
fut dominée par les lignages qypšaq qui avaient déjà soutenu la révolte de Kenesary dans la première moitié du $\mathrm{XIX}^{\mathrm{e}}$ siècle. Ces lignages élurent en novembre un khan en la personne d'Abdigapar Džanbosynov descendant du bij (juge) qypšaq Nijaz, qui avait été élevé au rang de sultan (titre réservé au töre) par Kenesary ${ }^{38}$. Džangil'din rejoignit la rébellion et $\mathrm{y}$ fut très actif.

Le soulèvement dans ces deux uezds fut critiqué par le journal Qazaq. Un article rédigé par un collectif d'intelligenty originaires de l'oblast en appelait à l'arrêt de la rébellion et à accepter la mobilisation ${ }^{39}$. Les auteurs étaient les rédacteurs en chef du journal, Bajtursunov et Dulatov, tous deux arghyn nés dans l'uezd de Turgaj, un fonctionnaire kazakh travaillant au tribunal régional d'Orenburg et originaire du même aul que Dulatov, Sejdazim Kadyrbaev, et Muhamed'jar Tungačin, interprète auprès du gouverneur de l'oblast et töre originaire de l'uezd d'Irgiz. Ils décrivaient la sanglante répression subie par les rebelles au Turkestan à la fin de l'été 1916 pour les prévenir de ce qui les attendait; ils assuraient aussi que les conditions de vie des mobilisés étaient satisfaisantes et les peurs infondées. Un Bureau des allogènes avait ouvert à l'automne à l'initiative de Bukejhanov pour venir en aide aux Kazakhs sur le front ${ }^{40}$. De nombreux jeunes étudiants, instituteurs et fonctionnaires kazakhs le rejoignirent et travaillèrent en collaboration avec les zemstvos $^{41}$ russes, dont dépendait le Bureau des allogènes. La rébellion dans l'uezd de Turgaj ne pouvait que compliquer leur tâche et leurs relations avec les autorités. Elle détériorait l'image que voulaient donner Bukejhanov et de nombreux intelligenty d'une population kazakhe intégrée à l'Empire et digne d'une citoyenneté à part entière. Personne ne pouvait s'imaginer que le renversement du régime tsariste était si proche. Il était donc essentiel pour eux de se dissocier des rebelles et de désavouer leurs actions. Ce consensus réunissait à la fois des intelligenty ayant fait le choix de la fonction publique et d'autres ayant œuvré au développement d'un discours politique anticolonial et qui subirent pour cela la répression du pouvoir russe. Dans les deux cas, la défense des droits des Kazakhs ne devait pas prendre la forme d'un affrontement armé, voué à l'échec selon eux. Džangil'din fut ainsi directement visé dans un article de Qazaq, qui le présenta comme un aventurier converti à l'orthodoxie avant de revenir à l'islam par opportunisme ${ }^{42}$. Il est notable qu'aucun représentant de la tribu qypšaq n'apparaît parmi les auteurs de ces articles.

À la veille de la révolution de février 1917, la situation des rebelles était critique. Seuls les lignages qypšaq de Džanbosynov et d'Imanov n'avaient pas encore déposé les armes. La rébellion avait été étouffée dans l'uezd d'Irgiz en janvier et les quelques lignages rebelles arghyn de l'uezd de Turgaj s'étaient soumis à l'autorité impériale à la fin de ce même mois. Les derniers rebelles étaient encerclés par les Cosaques et une offensive imminente les menaçait. Le changement de régime leur offrit un répit inespéré. L'opération de pacification de l'uezd fut suspendue et les rebelles bénéficièrent de l'amnistie proclamée par le Gouvernement provisoire russe, le 6 mars 1917. Toutefois, la question du rétablissement de l'ordre restait d'actualité.

Afin d'obtenir la levée de la loi martiale dans l'oblast de Turgaj, Džangil'din, à la tête d'une délégation, se rendit dans la capitale russe au début du mois de mars 1917. Il profita d'une connaissance bolchevique pour être introduit au soviet et put présenter sa requête en séance plénière $e^{43}$. Il reçut l'assurance que le soviet interviendrait pour mettre un terme à la répression. La loi martiale fut effectivement levée peu après ${ }^{44}$. Il lui aurait aussi été délivré un mandat pour organiser des soviets dans son oblast. 

débutait ainsi : « Le Kazakh Alibi Džangel'din, Qypšaq de l'uezd de Turgaj » (näsìlì Qypšaq, Torghaj uezìnìng Qazaghy Älì Žankeldìn) ${ }^{46}$. Le conflit révélait en effet la division entre des lignages qypšaq et arghyn. D'un côté, Almasov accusait la bande d'Imanov d'exactions contre des aul arghyn, de l'autre Džangil'din dénonçait la répression que subissaient les Qypšaq ${ }^{47}$. Hormis Bukejhanov d'origine töre, les autres responsables du Comité régional kazakh, Bajtursunov, Dulatov, Kadyr-baev et Ahmet Birimžanov appartenaient tous à la tribu arghyn. Afin d'éviter un conflit ouvert entre Qypšaq et Arghyn, Bajkadam Karaldin se rapprocha de Bajtursunov et s'efforça de trouver un terrain d'entente ${ }^{48}$. Bajtursunov, pédagogue et journaliste très respecté, était connu pour ses idées progressistes et son dévouement à la cause kazakhe. La situation resta néanmoins tendue pendant toute l'année 1917. 
Qypšaq de l'uezd de Turgaj et dans une vision politique plus large de création de soviets kazakhs. Džangil'din, Imanov ou Karaldin avaient une même volonté de défendre les droits des leurs et, de manière plus générale, de participer à l'instauration d'une administration plus juste pour les Kazakhs. Néanmoins, il semble peu probable que les deux derniers aient partagé l'orientation bolchevique ou même soviétique du premier.

Même si les efforts de Džangil'din pour créer des soviets kazakhs n'aboutirent pas, il chercha à obtenir le soutien des soviets locaux et panrusses face à Bukej-hanov et aux commissaires des uezds, qui pouvaient de leur côté s'appuyer sur l'autorité du Gouvernement provisoire. Après avoir promis de quitter sa région, il se serait rendu à Petrograd au tout début de l'été pour obtenir un mandat du soviet et reprendre son travail d'agitation dans l'oblast de Turgaj. Il rencontra à son retour de la capitale Aleksandr Korostelev, le président du soviet d'Orenburg, qui lui confirma son mandat. Lors de ce passage à Orenburg, Džangil'din intervint au soviet pour dénoncer les agissements du groupe de Bukejhanov dans l'uezd de Turgaj ${ }^{49}$. Il demanda la démission des commissaires en poste et l'élection de nouveaux.

Džangil'din revint dans son oblast et participa à nouveau à des meetings à Aktjubinsk, Turgaj et Irgiz, sans intégrer pour autant aucun soviet, ni comité kazakh ou zemstvo. Le mandat qu'il avait reçu ne garantissait pas sa liberté d'action. L'autorité au sein de la population kazakhe était détenue par les commissaires du Gouvernement provisoire et les comités kazakhs, qui ne reconnaissaient pas la légitimité du pouvoir des soviets sur les Kazakhs. Les soviets locaux, composés essentiellement de Russes, étaient eux-mêmes peu intéressés par le sort des Kazakhs. La répression touchant les bolcheviks à la suite des journées de juillet 1917 incita les forces politiques locales à s'attaquer aux faibles groupes bolcheviks présents dans l'oblast de Turgaj. Džangil'din en subit aussi les effets et, dès août, il fut à nouveau contraint par Bukejhanov à s'exiler, sans que Korostelev ne se porte à son secours. Džangil'din n'était pas parvenu à créer le moindre soviet au sein de la population kazakhe, qui restait étrangère à cette forme de mobilisation politique. Aucun soviet kazakh ne s'était encore constitué dans les steppes.

Il aurait pu trouver refuge auprès des siens, comme beaucoup de Kazakhs le firent durant la guerre civile, mais il préféra retourner, une fois de plus, à Petrograd. Il reprit contact avec la fraction bolchevique du soviet, qui lui fit suivre une formation courte d'instructeur du parti durant le mois de septembre ${ }^{50}$. La route des steppes lui étant barrée, il partit rejoindre sa femme en Crimée. Une nouvelle phase d'intense activité politique pour Džangil'din s'ouvrit seulement avec la révolution d'Octobre et la prise du pouvoir par les bolcheviks.

Les conflits au sein du paysage politique kazakh de l'oblast de Turgaj ne se limitèrent pas à ceux opposant Džangil'din et Imanov au groupe de Bukejhanov. En avril 1917, le premier congrès régional fut le théâtre d'une violente lutte d'influence qui aboutit à la victoire de Bukejhanov, Bajtursunov et Dulatov. Ce dernier attaqua Muhamed'jar Tungačin, délégué de l'uezd d'Irgiz, avec lequel il avait cosigné un article six mois auparavant pour convaincre les Kazakhs de l'inanité de se rebeller. Il dénonça sa collaboration avec les forces de police et son rôle dans la censure du journal Qazaq. Une des traductions de Tungačin avait notamment été à l'origine d'une condamnation de Bajtursunov en $1914^{51}$. Dulatov obtint le retrait de son mandat malgré le soutien des délégués d'Irgiz. Lors $\mathrm{du} \mathrm{II}^{\mathrm{e}}$ Congrès de l'oblast de Turgaj, les délégués d'Irgiz, majoritairement de la tribu älìmuly de la žüz cadette, tentèrent à nouveau de défendre sa 
cause, mais il ne fut jamais blanchi ${ }^{52}$. Il fut mis à l'écart de toute fonction de représentation dans les congrès ou les comités kazakhs.

Toujours lors du premier congrès régional, l'élection de Bajtursunov à la présidence du congrès ou encore la question agraire ${ }^{53}$ furent l'occasion d'autres échanges véhéments. Žihanša Sejdalin et Muhamedžan Seralin, deux figures influentes de l'intelligentsia originaire de l'oblast de Turgaj, l'un töre et l'autre qoža $a^{54}$, contestèrent la mainmise du groupe de Bukejhanov sur le congrès. Leur désaccord, qui avait notamment porté sur la sédentarisation et la place de l'islam, était ancien et s'était exprimé dans la presse kazakhe. Seralin avait été le rédacteur en chef du journal Ajqap, dont Sejdalin avait été un assidu collaborateur. Durant le congrès, Seralin défendit l'idée d'une mise en place immédiate d'une réforme agraire et notamment de la redistribution des terres attribuées aux colons russes, alors que le groupe de Bukejhanov s'alignait sur la décision du Gouvernement provisoire de charger la future Assemblée constituante de traiter cette question sensible. Seralin et Sejdalin eurent du mal à faire entendre leur voix et furent mis en minorité. Ils ne furent pas élus au nouveau comité régional et se retrouvèrent $d e$ facto exclus de la construction du mouvement national.

\section{L'oblast d'Ural'sk}

À la différence de la région de Turgaj, l'oblast d'Ural'sk présentait une plus grande homogénéité dans la composition des tribus, qui appartenaient toutes à la žüz cadette. Deux des quatre uezds étaient peuplés presque uniquement par la tribu bajuly, qui était aussi présente dans les deux autres uezds. La tribu žetìru était majoritaire dans l'uezd d'Ural'sk et la tribu älìmuly dans celui de Temir, mais elles restaient trois fois moins nombreuses que la tribu bajuly dans l'oblast. Les lignages töre descendant du khan Abulhair étaient aussi très présents avec leurs tölenggi ${ }^{55}$ et des lignages qaraqalpaq, qui se seraient soumis à l'autorité du khan Abulhair et qui l'auraient suivi au nord après 1740 pour s'installer dans le futur oblast d'Ural'sk ${ }^{56}$. S'appuyant sur un autre récit endogène, l'historien Allen Frank explique que ces lignages seraient en réalité des Tatars ayant fui la domination russe $\mathrm{au} \mathrm{XVIII}^{\mathrm{e}}$ siècle. Ils se seraient présentés devant les autorités russes comme des Qaraqalpaq originaires du khanat de Khiva pour justifier leur présence aux côtés de la zü̈z cadette ${ }^{57}$. En 1801, certains lignages accompagnèrent Bukej khan lors de la fondation de la Horde de Bukej, d'autres restèrent dans l'oblast d'Ural'sk.

Plusieurs réseaux se croisaient au sein des élites kazakhes de l'oblast. Bahytžan Karataev en fut au cœur avant 1917. Né en 1860 d'un lignage töre, il étudia le droit à l'université de Saint-Pétersbourg et exerça comme avocat. Député de l'oblast d'Ural'sk à la II ${ }^{\mathrm{e}}$ Duma d'État, il tenta de constituer une filiale kazakhe du Parti constitutionnel démocrate (KD) avec d'autres influents intelligenty des oblasts d'Ural'sk et de Turgaj, notamment Sejdalin et Seralin. Dans les années précédant la révolution de Février, Karataev collabora aux journaux Qazaqstan et Ajqap et devint le principal adversaire de Bukejhanov. La voie qu'il avait imaginée pour la modernisation de la société kazakhe reposait sur la sédentarisation et une islamisation inspirée par le réformisme musulman. Karataev joua aussi le rôle de mentor pour de nombreux jeunes étudiants kazakhs qu'il conseilla et aida financièrement. Il soutint notamment Žihanša Dosmuhamedov, futur président de la branche occidentale d'Alaš orda, et les frères Ipmagambetov qui appartenaient à un lignage qaraqalpaq. 

nodale. Plus jeune que Karataev, il tenait son aura politique de son engagement révolutionnaire en 1905, qui avait entraîné sa déportation en terre bouriate. Il avait adhéré au Parti socialiste révolutionnaire et fréquenta en Sibérie l'importante colonie de déportés politiques. De retour à Ural'sk après la révolution de février 1917, il réunit autour de lui des intelligenty sensibles aux idéaux socialistes: Muhamedhafij Murzagaliev, Abdrahman Ajtiev et Mendigerej Ipmagambetov. Murzagaliev était originaire du même volost qu'Argančeev et né la même année que lui, mais il appartenait à la tribu žetìru. Il participa à ses côtés aux événements de 1905, sans devenir un militant actif. Après des études à Saratov, il devint agronome dans cette gubernija. Abdrahman Ajtiev, également membre de la tribu žetìru, et Mendigerej Ipmagambetov avaient dix ans d'écart, mais ils se rapprochèrent alors qu'ils travaillaient dans l'administration du volost de Kara-Oba de l'uezd d'Ural'sk dans les années 1906-1910.

En mars 1917, Karataev, Argančeev, ainsi qu'Ajtiev et les frères Ipmagambetov s'associèrent à trois autres intelligenty influents, Gubajdulla Alibekov, Halel Dosmuhamedov et Dauletšah Kusepkaliev, pour former un comité kazakh régional provisoire et convoquer un congrès de l'oblast d'Ural'sk. Kusepkaliev, töre, et Halel Dosmuhamedov, de la tribu bajuly, étaient tous deux médecins militaires, tandis que Gubajdulla Alibekov, aussi de la tribu bajuly, était interprète auprès de l'administration régionale.

Dès le premier congrès régional kazakh, tenu à la fin du mois d'avril, le rapport de force tourna au désavantage de Karataev et d'Argančeev. Ceux-ci appartenaient à des lignages minoritaires et durent faire face aux représentants des lignages bajuly qui dominaient l'oblast. La présidence et les deux vice-présidences du praesidium revinrent à des membres de la tribu bajuly. Žihanša Dosmuhamedov, qui venait d'arriver de Tomsk, fut élu président et Alpysbaj Kalmenov, député de la Première Duma d'État russe en 1906, et Gubajdulla Alibekov, devinrent ses deux adjoints. Dans son livre Ternistij put' [le chemin épineux], qui retrace les événements de cette période, Saken Sejfullin évoque le rôle central de Salyk Omarov, gouverneur de volost et figure la plus influente de la tribu bajuly ${ }^{58}$. Sans briguer aucun poste, ni chercher à être élu au comité régional, il aurait pesé sur les choix politiques et les élections. Žihanša et Halel Dosmuhamedov, qui n'étaient pas du même lignage, mais de la même tribu, prirent la direction du nouveau comité kazakh régional. Karataev, qui bénéficiait pourtant d'une grande aura, fut réduit au silence. Accusé d'avoir servi l'ancien régime, il fut écarté des nouveaux organes kazakhs ${ }^{59}$. Si le facteur tribal est à nouveau absent des sources disponibles sur ce congrès à l'exception du récit de Sejfullin, les divergences politiques sont plus clairement explicitées. La place des femmes fut un des sujets polémiques. Karataev, dont la femme et les filles étaient intervenues lors du congrès, défendait leur droit à participer à la vie politique et leur émancipation dans la continuité du discours djadide. Salyk Omarov et des religieux conservateurs s'insurgèrent contre la présence des femmes au congrès et obtinrent satisfaction auprès du praesidium, qui ne put s'opposer à la volonté des élites tribales ${ }^{60}$. Le soutien du congrès au Gouvernement provisoire, en particulier à la poursuite de la guerre, ne fit pas non plus l'unanimité. Argančeev et Nurgali Ipmagambetov s'exprimèrent clairement contre la guerre, soutenus en cela par Karataev. Ipmagambetov, qui était médecin militaire, avait été déporté en Sibérie juste avant la révolution de février 1917 pour avoir réformé des allogènes par complaisance ${ }^{61}$.

Cahiers du monde russe, $56 / 4$ | 2015 
Au sein des groupes de Karataev et d'Argančeev, seul Nurgali Ipmagambetov participa au mouvement national, tout en maintenant son opposition à certaines orientations du comité régional. Les questions sociales étaient un enjeu primordial et le débat concerna la délimitation de l'imposition des Kazakhs, à savoir l'introduction d'une modulation de son calcul selon les revenus. Les divergences furent exprimées lors du deuxième congrès régional en juin. Ipmagambetov, qui fut élu par la suite à la direction du zemstvo de l'uezd d'Ural'sk, s'allia à Aliaskar Alibekov pour dénoncer la ligne conservatrice instiguée par Halel et Žihanša Dosmuhamedov. Aliaskar Alibekov, jeune cousin de Gubajdulla Alibekov, avait étudié aux côtés de Murzagaliev et resta toujours très proche de lui. Aliaskar et Nurgali furent largement minoritaires au congrès, même s'ils réunirent un petit groupe autour d'eux. Toutefois, il n'était pas question de rompre avec le comité régional. Nurgali Ipmagambetov excepté, les membres de ce groupe appartenaient tous à la tribu bajuly et pouvaient difficilement se désolidariser de leurs élites et des intelligenty de leur lignage.

Le rôle politique des membres du groupe de Karataev et d'Argančeev se limita à leur volost, où ils restèrent influents. Ils purent en général compter sur le soutien de leur lignage. Mendigerej Ipmagambetov et Ajtiev furent élus au zemstvo de leur volost, tout comme Imanov l'avait été dans celui de l'uezd d'Ural'sk ${ }^{62}$. La mise à l'écart du mouvement national kazakh n'impliqua pas le ralliement à un parti révolutionnaire. Durant la période précédant la révolution d'Octobre, aucun de ces Kazakhs n'adhéra à un quelconque parti, même s'ils furent sensibles à certains slogans et en contact avec des bolcheviks, mencheviks, socialistes révolutionnaires, anarchistes (...) russes ou tatars. Le modèle soviétique ne fut pas plus populaire parmi les Kazakhs de l'oblast d'Ural'sk qu'il ne l'avait été à Turgaj. La forme d'orga-nisation privilégiée resta le zemstvo, dont les populations de Sibérie et d'Asie centrale n'avaient pas pu bénéficier avant 1917. Leur création avait répondu à l'une des principales revendications exprimées par l'intelligentsia kazakhe.

\section{La Horde de Bukej}

Dans la Horde de Bukej rebaptisée Steppe kirghize de la gubernija d'Astrahan' ${ }^{63}$, la composition tribale était relativement homogène: une majorité écrasante de représentants de la tribu bajuly, une présence notable de töre et de lignages tölenggit et une petite minorité noghaj ${ }^{64}$, présente dans le nord de la Horde de Bukej ${ }^{65}$. Les colons russes étaient nettement moins présents dans la région que dans les autres oblast et aucune stanitsa cosaque n'y avait été implantée.

48 À la suite de ce qui s'était passé dans l'oblast de Turgaj en mars 1917, un groupe d' intelligenty organisa un premier comité provisoire kazakh pour préparer le congrès régional. Il réunit les principales figures politiques régionales: les töre, Bahtygerej Kulmanov et Gabdulgaziz Musagaliev, un représentant de la tribu bajuly, Vali Tanašev, deux de la tribu noghaj, Batyrhajyr Nijazov et Mažit Čumbalov, et les tölenggit Sejtkali Mendešev et Išangaly Mendihanov. Kulmanov et Nijazov avaient occupé le poste de gouverneur de volost pendant de longues années. Kulmanov, aîné des lignages töre de la Horde de Bukej, fut député aux deux Premières Dumas d'État et Nijazov avait autorité sur de nombreux lignages de la tribu noghaj. Tanašev, avocat à Kazan, dont le père fut un des rares Kazakhs à porter le titre de marchand de la première guilde, appartenait à une des familles les plus riches de Bukej ${ }^{66}$. Plusieurs de ses membres avaient aussi été impliqués dans la création du journal Qazaqstan aux côtés de Karataev: Nijazov, Mendešev et 
Musagaliev qui en fut un des rédacteurs en chef. Ce dernier, ainsi que Gumar Karašev, issu de la tribu noghaj et collaborateur du Muftiat d'Ufa, furent parmi les principales voix du courant religieux réformiste kazakh. Du fait de la proximité avec les centres musulmans tatars, ce courant était très présent dans la Horde de Bukej et dans l'oblast d'Ural'sk.

Lors du premier congrès régional qui réunit les représentants des volosts à la fin avril, Kulmanov fut élu commissaire de Bukej et Mendihanov devint son vice-commissaire. La principale préoccupation fut d'assurer l'existence d'une entité administrative et politique propre à la Horde de Bukej ${ }^{67}$. Les principes démocratiques furent aussi clairement exprimés et, ici comme dans les autres oblasts il ne fut pas plus question de créer des soviets. Un des groupes du comité provisoire kazakh, autour de Nijazov, Čumbalov et Mendihanov, se définissait comme "démocrate autochtone " (žergiliktì demokrat) ${ }^{68}$. Un courant d'obédience plus socialiste s'était aussi manifesté autour de Mustafa Kukebaev, aide-vétérinaire à Astrahan' et sympathisant menchevik, et de Sejtkali Mendešev, instituteur emprisonné en 1916 pour sa participation à la rébellion ${ }^{69}$.

\section{Les oblasts d'Akmolinsk et de Semipalatinsk}

Dans les deux oblasts du Gouvernorat des steppes, les tribus représentées appartenaient toutes à la žüz moyenne et les trois principales étaient celles des Arghyn, des Najman et des Kerej. Au cours de l'année 1917, les congrès et les comités régionaux kazakhs y furent parfaitement contrôlés par la tribu arghyn qui était la plus nombreuse $\mathrm{e}^{70}$. La présidence du comité kazakh de l'oblast d'Akmolinsk revint à Ajdarhan Turlybaev, avocat à Omsk, et Sejlbek Žanajdarov, issu d'un très influent lignage arghyn de l'uezd d'Atbasar et diplômé de la faculté de droit de l'université de Saint-Pétersbourg, en devint le vice-président. Dans l'oblast de Semipalatinsk, ces postes furent occupés respectivement par Žakyp Akpaev, avocat célèbre pour sa défense des droits des Kazakhs, et Halel Gabbasov, comptable à Semipalatinsk.

Le tableau était cependant différent localement. Les deux uezds orientaux de l'oblast de Semipalatinsk, à majorité najman ${ }^{71}$, restèrent à l'écart du mouvement national. Un seul représentant najman, originaire de l'uezd de Zajsan, intégra le comité de l'oblast de Semipalatinsk ${ }^{72}$. Dans l'uezd d'Ust'-Kamenogorsk, Amre Ajtbakin, qui avait exercé en tant que médecin dans les deux uezds orientaux, avait une grande autorité. Né en 1859 dans l'uezd de Pavlodar, il était issu d'une riche famille de la tribu arghyn et avait étudié à Tomsk, cœur du mouvement régionaliste sibérien. En 1906, lors du choix du candidat kazakh de l'oblast de Semipalatinsk pour la Première Duma d'État, il s'était présenté contre Bukejhanov. Il avait reçu le soutien de certains grands électeurs najman des uezds orientaux, mais il échoua et ne se réconcilia jamais avec Bukejhanov. Il resta tout aussi circonspect face au mouvement national kazakh. La domination arghyn dans le comité et les congrès de l'oblast renforçait la défiance des Kazakhs de ces uezds.

Dans l'uezd d'Omsk, qui était partagé entre lignages kerej et arghyn, le comité kazakh fut présidé par Mukan Ajtpenov de la tribu kerej et les tensions avec le comité régional furent vives. Dans l'uezd d'Atbasar, partagé entre des lignages arghyn et najman, la lutte d'influence entre les représentants des deux tribus fut violente dans la première moitié de 1917, avant que les élites tribales ne parviennent à s'entendre.

Les organisations de jeunesse constituèrent aussi des lieux d'expression des divergences politiques. Bìrlìk [l'unité], créée à Omsk en 1915, était la plus célèbre des associations étudiantes kazakhes. Un grand nombre de jeunes intelligenty des oblasts d'Akmolinsk et de 
Semipalatinsk était passé par ses rangs. Elle continua d'être active après la révolution de Février, réunissant non seulement des étudiants, mais aussi des jeunes diplômés ou des fonctionnaires, qui appartenaient à toutes les tribus. Elle regroupait des sensibilités politiques diverses et resta neutre en 1917 dans les conflits internes au mouvement national kazakh, tout en y étant partie prenante. À l'été 1917, ses anciens membres, Saken Sejfullin et Abdolla Asylbekov, fondèrent une nouvelle organisation à Akmolinsk, qu'ils dénommèrent Žas Qazaq [la jeunesse kazakhe]. Sejfullin, issu d'un des plus influents lignages arghyn de l'uezd, prit la vice-présidence du comité kazakh local en avril 1917, avant d'en être écarté cinq mois plus tard au congrès de l'uezd. Il avait pourtant participé au $\mathrm{I}^{\mathrm{er}}$ Congrès pankazakh de juillet et avait été inclus dans la liste des candidats à l'Assemblée constituante. Mais il prit ses distances avec le groupe de Bukejhanov, exigeant de donner une orientation plus sociale au mouvement national. Il aurait notamment refusé de s'associer à d'anciens gouverneurs de volost ou à de puissants $b \mathrm{bj}^{73}$ kazakhs qui avaient abusé de leur pouvoir. L'action de Sejfullin au comité local consista à créer des comités kazakhs de volost et d'aul, afin de mettre en place les bases d'une administration. Il ne chercha pas plus que dans les autres régions mentionnées à ouvrir des soviets.

Les seconds congrès régionaux, tenus à l'été 1917 dans les différents oblasts, renforcèrent les positions déjà occupées et élurent leurs représentants au $\mathrm{I}^{\mathrm{er}}$ Congrès pankazakh, qui définit les grandes orientations du mouvement national kazakh. La reconnaissance d'une autonomie nationale dans le cadre d'une Russie fédérative et démocratique et la demande d'une autorité religieuse propre aux Kazakhs en furent les deux points principaux. La question agraire était laissée en suspens jusqu'à la tenue de la Constituante, mais l'arrêt de l'expropriation des terres et la restitution de celles non encore attribuées furent exigés. Le principe d'une imposition différenciée entre riches et pauvres fut discuté, mais il ne fut pas inscrit dans les résolutions du congrès. Il ne fut pas non plus question de l'organisation de soviets, mais de zemstvos. L'orientation générale était modérée, sans remise en cause des structures de la société kazakhe.

55 Ce congrès entérina la proposition de Bukejhanov de créer un parti kazakh, dénommé Alaš ${ }^{74}$, pour représenter l'ensemble de la population kazakhe à l'Assemblée constituante. Un programme, conçu pour incarner le mouvement national, fut rédigé à la suite de cette résolution et des comités Alaš virent le jour dans les oblasts de Semipalatinsk, d'Akmolinsk et de Turgaj. Toutefois, aucun comité d'Alaš ne fut organisé dans l'oblast d'Ural'sk ou dans la Horde de Bukej, territoires de la žüz cadette. En août, Dulatov s'était inquiété des effets centrifuges de la division tribale kazakhe: «Si nous choisissons nos représentants [à l'Assemblée constituante] selon l'appartenance à une tribu ou à une žüz, nous nous perdrons à jamais comme nation et nous n'aurons aucun avenir $»^{75}$.

\section{Deuxième phase : quels choix pour les Kazakhs après la révolution d'octobre 1917 ?}

L'attitude des groupes de Bukejhanov et des Dosmuhamedov, qui avaient monopolisé la représentativité des Kazakhs au cours de 1917, ne laissait aucune place à d'autres voix dans le mouvement national. Ils martelaient l'idée de la nécessaire unité face aux Russes, qui supposait de s'aligner sur une plateforme politique unique en dépit des profondes divergences. Bukejhanov avait imposé le principe d'un parti unique, le parti Alaš, pour représenter les Kazakhs à l'Assemblée constituante. Toute autre initiative était 
déconsidérée et fortement critiquée dans la presse, dont les titres les plus diffusés, Qazaq et Sary-Arqa ${ }^{76}$, étaient contrôlés par le groupe de Bukejhanov. De grands espoirs furent mis dans la convocation de l'Assemblée constituante, dont les élections furent fixées à novembre après des mois de tergiversations. Leur résultat marqua clairement la domination du parti Alaš et des listes établies par les congrès régionaux. Il est difficile d'analyser les résultats en l'absence d'études sur ce sujet.

Le second congrès pankazakh, qui se tint après la révolution d'Octobre, entre le 5 et le 13 décembre, exprima un rejet sans équivoque du pouvoir soviétique. La question centrale avait été d'élaborer la meilleure stratégie pour garantir l'autonomie. Le débat avait porté sur le choix d'une autorité de tutelle, en l'absence d'une armée et de structures étatiques kazakhes: autonomie turkestanaise ${ }^{77}$, Gouvernement provisoire sibérien $^{78}$ ou Union du Sud-Est des Cosaques, des montagnards du Caucase et des peuples libres des steppes ${ }^{79}$. L'instabilité politique rendait le futur incertain. Un conseil national nommé Alaš orda fut élu pour organiser et diriger la future autonomie. Sa composition confirma la prédominance de leaders des deux principales tribus, arghyn et bajuly, et Bukejhanov en devint le président.

L'opposition au mouvement national kazakh, active essentiellement en milieu urbain, resta très minoritaire, mais elle prit de l'assurance grâce à la montée en puissance des soviets face au Gouvernement provisoire aussi bien à Petrograd que localement. Le rapprochement avec les soviets s'échelonna selon les cas entre l'automne et l'hiver 1917-1918. Il fut facilité par l'hostilité du mouvement national vis-à-vis des soviets et le refus catégorique de ses membres d'y participer. Cette absence profita à ceux qui avaient été marginalisés: la révolution d'Octobre et la prise du pouvoir par les soviets redistribuèrent les cartes $d u$ pouvoir en leur faveur. Ils reprirent la rhétorique révolutionnaire, s'adjugeant le rôle de représentants du peuple kazakh dans les soviets, et participèrent au développement des soviets parmi leurs compatriotes.

Les slogans sur la justice sociale, la mise en place immédiate d'une réforme agraire et l'imposition progressive se diffusèrent aux côtés du principe de démocratie populaire que les soviets étaient censés exprimer. L'oppression des tribus ou des lignages puissants à l'endroit des plus faibles était une source de tensions et de conflits, ainsi que l'absence d'un renouvellement du paysage politique local kazakh. Des gouverneurs de volost avaient été critiqués pour leur corruption et gardèrent leur position, tout en bénéficiant du soutien des comités régionaux kazakhs, qui étaient aussi partiellement dépendants de ces notables locaux.

De leur côté, les nouvelles autorités soviétiques restaient étrangères à la majeure partie de la population kazakhe, qui n'était toujours pas représentée dans les soviets au début de l'année 1918. Confrontées à la nécessité d'intégrer les Kazakhs dans le nouveau régime, elles devaient s'assurer le concours d'intermédiaires pour affirmer leur pouvoir et ouvrir des soviets kazakhs. Le gouvernement soviétique s'inquiétait, avant tout, de la représentativité de leurs interlocuteurs, c'est à dire de la capacité à mobiliser et à contrôler la population kazakhe. Moscou, comme les soviets locaux dominés par les Russes, avait peu de considération pour les nomades. Lors d'une réunion d'avril $1918 \mathrm{du}$ Soviet de Saratov, son président déclara en présence de Halel Dosmuhamedov :

La condition d'opprimé des Kirghiz a développé chez eux une mentalité d'esclaves fourbes. Ils sont habitués à se soumettre au pouvoir de la force. Ils disent : «celui qui ne nous égorge pas, celui qui nous défend, nous sommes avec lui ». Mais, ils choisissent le plus fort. Ils seront avec nous tant que nous serons plus forts. ${ }^{80}$ 
Les bolcheviks ne cherchaient pas à s'appuyer sur un prolétariat kazakh inexistant, mais à garantir l'apparence soviétique des organes nationaux. Il exista toujours une certaine tension entre les soviets russes et les Kazakhs ralliés au pouvoir soviétique. Le pouvoir bolchevik était sceptique quant à la loyauté de ces différents groupes, qui n'avaient eu aucune activité révolutionnaire avant 1917. Seul Džangil'din, bolchevik depuis 1915, bénéficiait de la confiance relative des leaders bolcheviks.

\section{Le parti Üš žüz dans les oblasts d'Akmolinsk et de Semipalatinsk}

Si la plupart des groupes écartés ou opposés au mouvement national n'étaient pas parvenus à créer les bases d'une organisation politique propre, le cas du parti Üš žüz [les trois hordes] s'en distingue ${ }^{81}$. Il fut fondé entre les mois d'octobre et de novembre 1917, afin de présenter une liste concurrente à celle du parti Alaš pour les élections à l'Assemblée constituante. Son apparition fut le fruit de l'association entre deux figures connues d'Omsk, Šajmerden Alžanov et Mukan Ajtpenov, et Kol'baj Togusov, installé dans cette ville seulement depuis l'été 1917.

Originaire de l'est de l'oblast de Semipalatinsk, Togusov appartenait à un lignage renommé et très religieux de la tribu najman. Il travailla comme interprète auprès du juge de Karkaralinsk de 1900 à 1907, puis exerça en tant qu'avocat, sans justifier d'aucun diplôme. Il affirma sa légitimité révolutionnaire et nationale en s'appuyant sur ses activités d'avocat et de publiciste, qui lui valurent deux arrestations en 1909 et 1910 et un exil au Turkestan à partir de 1912. Les années 1910-1912 furent aussi le moment d'une rupture avec les principaux milieux de l'intelligentsia kazakhe qui le considérèrent comme un personnage trouble. Il vivait à Taškent depuis 1916 et y publia le journal Alaš. En mai 1917, il s'invita dans la délégation turkestanaise au Congrès panrusse des musulmans. Il fut élu au Conseil central des musulmans, mais sa présence fut dénoncée par le Šura-i-islamija ${ }^{82}$ qui ne l'avait pas mandaté et il dut abandonner son poste. Il retourna dans son uezd natal de Zajsan et y participa au congrès des Kazakhs, avant de partir pour Omsk. Son frère Sulejman adhéra aussi au parti Üš žüz et Ishak Kabekov, un Najman de l'uezd de Zajsan qui étudiait la médecine à Omsk, en fut le secrétaire.

Šajmerden Alžanov et Mukan Ajtpenov appartenaient tous deux à la tribu kerej. Avant la révolution de février 1917, Ajtpenov était interprète auprès du gouverneur de l'oblast d'Akmolinsk. D'une riche famille, il aida et logea de nombreux jeunes Kerej venus étudier à Omsk. Ce fut notamment le cas d'Abulhair Dosov et de Žanajdar Sadvokasov. Élu président du comité kazakh de l'uezd d'Omsk au printemps 1917, Ajtpenov était le plus à même de recueillir le soutien des lignages kerej et fut choisi pour présider le parti Üš žüz. Šajmerden Alžanov était un personnage plus marginal. Il travaillait à l'hôpital d'Omsk et était en même temps imam dans une des mosquées tataro-kazakhes de la ville. Son influence n'était pas que religieuse. Il fut aussi un des membres fondateurs de Bìrlìk, l'association étudiante d'Omsk. Alžanov et Togusov avaient collaboré au journal Ajqap, concurrent de Qazaq. Le Comité central du parti comprenait, en plus des cinq personnes citées, un révolutionnaire tatar social-démocrate, Karim Sutišev, qui avait été élu au Soviet de Petropavlovsk dès mars 1917.

65 Les sources sur la composition du parti sont peu nombreuses. D'après les éléments collectés, il semble que le parti recruta majoritairement dans la tribu kerej et, en moindre mesure, parmi les Najman et les Qypšaq ${ }^{83}$. L'implantation du parti suivit la répartition des Kerej dans l'oblast d'Akmolinsk avec des organisations présentes à Omsk, Petropavlovsk 
et Kokčetav. La tribu kerej était très présente dans les uezds d'Omsk, de Petropavlovsk et à un niveau plus faible dans ceux de Kokčetav et d'Akmolinsk ${ }^{84}$. Il ne se développa pas dans l'uezd de Zajsan, malgré les efforts des deux frères Togusov et de Kabekov et ne fut pas mieux représenté dans les autres uezds de l'oblast de Semipalatinsk. Il comprenait une majorité de jeunes, des instituteurs, des artisans, des ouvriers et des petits employés kazakhs et tatars vivant dans les villes de la région. Leur nombre est estimé à environ 600-700 à la fin de 1917.

Les positions initiales de ce parti, défendues dans le journal Üš žüz publié à Petropavlovsk, étaient une synthèse entre socialisme, unité des peuples turko-tatars et islam. Le choix de l'intitulé se voulait une réponse au parti Alaš pour s'attribuer une légitimité nationale. Si Alaš était l'ancêtre mythique commun aux Kazakhs, les trois hordes ou žüz réunissaient l'ensemble des tribus kazakhes. Une déclaration fut envoyée aux différentes organisations kazakhes :

Mécontents du programme du parti Alaš, créé par le KD Bukejhanov ${ }^{85}$, des Kazakhs ont formé un parti socialiste sous le nom de Üš-žüz. Le but de ce parti est de soutenir la fédération, d'organiser une nouvelle communauté turko-tatare et d'établir des listes pour les élections à l'Assemblée constituante. ${ }^{86}$

67 La ligne politique n'était pas homogène, entre une position modérée représentée par Ajtpenov et une orientation plus radicale exprimée par Togusov et Alžanov. Le parti affirmait sa légitimité par rapport au parti Alaš, sur son caractère socialiste, qui impliquait pour eux la défense des intérêts des pauvres kazakhs, nommés kedej (pauvres) ou buqara (dépendants). Bien que le parti affichât son obédience socialiste, à sa création, il ne se positionnait pas sur une orientation soviétique et encore moins bolchevique. Le dessein était de prendre le contrôle des comités kazakhs et non de créer des soviets kazakhs.

Fin octobre, le parti Üš-žüz tenta une première fois de renverser le comité kazakh de l'oblast d'Akmolinsk. À l'issue d'un meeting à Omsk, les leaders du parti entraînèrent la foule vers le bâtiment du comité régional et arrêtèrent les membres et collaborateurs présents. Le président Ajdarhan Turlybaev était absent. Ils se dirigèrent donc vers sa maison pour le forcer à démissionner de ses fonctions. Avant qu'ils aient pu enfoncer la porte, les forces de police avaient dispersé la foule. Les personnes arrêtées furent relâchées. Le conflit entre le parti Alaš et le parti Üš žüz était lancé. Les journaux Qazaq et Sary-Arqa publièrent de nombreux articles décriant les agissements du parti et de ses membres. Les résultats aux élections à l'Assemblée constituante montrent le déséquilibre entre les deux forces et l'incapacité du parti Üš žüz à mobiliser au-delà d'un cercle très limité. Sa liste obtint 50 voix dans l'uezd d'Omsk, 164 dans l'uezd de Kokčetav, 4 dans l'uezd de Petropavlovsk et 2 dans l'uezd de Semipalatinsk. Aucune étude n'a toutefois été menée sur le détail de ce vote.

69 Au mois de décembre 1917, le parti Üš žüz, qui avait reconnu le nouveau régime, rallia ostensiblement les organes soviétiques régionaux. La déclaration de Lenin adressée aux musulmans de Russie et d'Orient le 20 novembre 1917 joua son rôle. Dès lors, le parti Üš žüz s'efforça de fonder sa ligne politique sur celle des partis bolchevik et socialiste révolutionnaire de gauche. Une déclaration notait qu'

aucun gouvernement ni russe ni européen n'avait parlé cette langue avec les musulmans. [...] La lutte contre l'impérialisme, proclamée par la démocratie russe [le gouvernement soviétique], apportera la libération des pays musulmans de l'exploitation du capital européen et les libérera du danger de morcellement constant. ${ }^{87}$ 

sur des positions qu'il jugeait trop radicales. La perte des élections joua certainement aussi dans sa décision de se désengager du parti. Togusov le remplaça au poste de président. Pour autant, ni les soviets locaux ni les bolcheviks ne considéraient le parti Üš žüz comme un réel partenaire. Le programme du parti Üš žüz n'entrait pas dans leur cadre : il y défendait notamment une autonomie centrasiatique, une justice basée sur l' adat et la charia, des zemstvos pour les aul ${ }^{88}$ et la sédentarisation ${ }^{89}$.

et les soviets locaux cherchaient des interlocuteurs kazakhs, alors qu'ils n'avaient aucune idée du paysage politique kazakh. Leur hésitation était grande dans les premiers mois de 1918. En janvier-février 1918, Džangil'din fut ainsi chargé par Moscou de se renseigner sur Togusov et le parti Üš-žüz, afin de savoir s'ils étaient suffisamment proches du pouvoir soviétique pour être utilisés comme contre-pouvoir face à Alaš orda ${ }^{90}$. De son côté, le soviet régional d'Omsk coopta Togusov dans le courant du mois de janvier et le nomma commissaire aux biens d'État des oblasts de Semipalatinsk et d'Akmolinsk. Togusov fut très démonstratif dans son ralliement au nouveau régime et très virulent à l'endroit d'Alaš orda ${ }^{91}$. Son activité était tournée vers la dissolution des comités kazakhs toujours en place, puis vers la neutralisation d'Alaš orda. Il n'était toutefois toujours pas question pour lui ni d'adhérer au parti bolchevik, ni d'organiser des soviets kazakhs. Son but était de remplacer les membres des comités kazakhs existants par ses partisans et de les préserver comme organe de représentation de la population kazakhe.

Entre la fin du mois de février et les premiers jours de mars, il convainquit le soviet d'Omsk de dissoudre le comité kazakh de l'oblast d'Akmolinsk, le remplaçant par un nouveau sous la présidence d'Alžanov. Togusov négocia alors quatre places au comité exécutif des soviets de Sibérie occidentale pour représenter ce nouveau comité régional qu'il assimila à un soviet. La manœuvre fut répétée à Petropavlovsk au début du mois de mars et un nouveau comité kazakh de l'uezd, contrôlé par le parti Üš-žüz, fut nommé.

Dans le même temps, un télégramme fut envoyé à Akmolinsk pour informer Sejfullin et son organisation Žas Qazaq de ces changements et les inciter à les imiter. Bien que le comité kazakh de l'uezd d'Akmolinsk fût alors dissout, un nouveau comité ne fut pas nommé, Sejfullin préférant fusionner avec le soviet. Les positions de Sejfullin et d'Asylbekov, les deux leaders de Žas Qazaq, étaient très différentes de celle du parti Üš-žüz, auquel ils avaient toujours refusé d'adhérer ${ }^{92}$. La distance prise avec ce parti était certainement due en partie à sa connotation kerej, alors que tous deux étaient arghyn. Sejfullin et Asylbekov gardèrent une attitude neutre dans le conflit entre le parti Alaš et le parti Üš-žüz. Entre la fin de 1917 et le début de 1918, ils ne pouvaient s'opposer ouvertement au parti Alaš qui représentait leur tribu arghyn. Les points du programme du parti Ǚs-žüz sur l'islam et la fédération turko-tatare leur étaient aussi étrangers. Leurs activités militantes depuis l'automne 1917 les avaient rapprochés des membres locaux du parti bolchevik, dont ils devinrent membres en février 1918.

74 Togusov tenta aussi de dissoudre le comité régional de l'oblast de Semipalatinsk. Il s'appuya sur un des rares membres de son parti vivant à Semipalatinsk: Nurgali Kulžanov, originaire de l'uezd de Turgaj et professeur de russe et de littérature à l'école normale de la ville depuis 1905. Loin de son lignage, sa décision était un choix individuel. Son opposition au parti Alaš puis à Alaš orda résidait dans une approche différente du chemin à parcourir vers l'autonomie politique. Kulžanov était très impliqué dans la collecte de folklore kazakh et dans la promotion de la littérature et de nouveaux médias 
culturels parmi les Kazakhs. Il était en revanche persuadé que la société kazakhe n'était pas encore prête pour se développer sans tuteur. Le territoire revendiqué était aussi, selon lui, trop étendu pour établir un État stable. Il s'opposa ainsi au projet d'autonomie décidé par le congrès pankazakh de décembre 1917, présentant comme une chimère l'idée d'une neutralité de la future entité kazakhe ${ }^{93}$. Dans un article de janvier 1918, il se prononça contre la voie «révolutionnaire» d'une proclamation immédiate de l'autonomie et pour une voie dite "évolutionniste» d'une construction progressive. Comme les autres membres du parti Üš žüz, il n'adhéra pas au parti bolchevik, mais il intégra le soviet de Semipalatinsk. Trop isolé dans la ville où siégeait Alaš orda et qui ne fut sous le contrôle des soviets qu'à la fin février, il ne réussit pas à constituer un nouvel organe kazakh régional.

Amre Ajtbakin, à la tête du comité kazakh de l'uezd d'Ust'-Kamenogorsk, avait une analyse similaire. Il estimait que l'autonomie n'apporterait pas aux Kazakhs le développement culturel, social et politique espéré. Il préférait associer le destin des deux uezds au Gouvernement provisoire sibérien. Dans les deux uezds orientaux de l'oblast de Semipalatinsk, l'implantation d'Alaš orda fut un échec, sans pour autant ouvrir la voie aux soviets ou au parti Üš žüz ${ }^{94}$. Les comités kazakhs locaux refusèrent de reconnaître l'autorité du conseil national, mais constituèrent des zemstvos. Les invitations du parti Üš žüz furent aussi déclinées.

76 Parallèlement aux dissolutions des comités kazakhs, le parti Alaš et Alaš orda, qui fusionnèrent dans les deux oblasts orientaux, furent directement visés par Togusov, qui demanda leur liquidation et l'arrestation de ses membres. Même si quelques membres furent effectivement arrêtés, Alaš orda réussit à se maintenir, car ni les soviets ni le parti Üš-žüz n'avaient de forces ni d'implantations suffisantes dans les steppes pour l'éliminer.

L'association étudiante Bìrlìk ne resta pas en dehors de cette lutte de pouvoir. Si sa position avait plutôt été neutre malgré des débats internes houleux jusqu'au printemps 1918, la situation changea avec la stratégie de Togusov. Une scission de l'organisation fut provoquée avec la création d'une Union démocratique de la jeunesse, dont les principaux leaders étaient deux membres du parti Üš žüz, Dosov et Žajnadar Sadvokasov. Toutefois, la majorité de Bìrlìk soutint Alaš orda.

$78 \mathrm{Au}$ cours du mois de mars, une nouvelle orientation politique se dessina. Depuis février 1918, le Commissariat du peuple aux nationalités (NKN) s'attachait à créer des commissariats nationaux afin de préparer la future constitution de la République soviétique fédérative socialiste de Russie (RSFSR), proclamée en janvier 1918, et d'y intégrer de nouvelles entités nationales ${ }^{95}$. La difficulté consistait à trouver des personnes avec lesquelles collaborer pour installer le pouvoir soviétique dans la steppe kazakhe. À la différence du parti Üš žüz, Alaš orda apparaissait alors, par son caractère national et par sa présence politique aussi bien dans les oblasts occidentaux qu'orientaux, comme l'interlocuteur le plus valable pour réaliser cet objectif. Les efforts du parti Üš-žüz pour discréditer le parti Alaš et le conseil national aux yeux du pouvoir soviétique n'eurent aucun résultat, Moscou négociait avec Alaš orda en connaissance de cause ${ }^{96}$.

79 La collaboration des soviets avec le parti Üš žüz fut même mise en question par les agissements de Togusov et d'Alžanov. Les divergences avec Ajtpenov les poussèrent à le faire arrêter, mais, dans l'uezd d'Omsk, celui-ci était une figure bien plus influente que les deux précédents. Les partisans d'Ajtpenov protestèrent auprès du soviet d'Omsk et obtinrent satisfaction ${ }^{97}$. À leur tour, Togusov et Alžanov furent accusés de corruption et d'abus de pouvoir. Alaš orda en profita pour dénigrer le parti Üš-žüz, dépeint comme un 
ramassis de criminels et de nationalistes réactionnaires. Le 23 avril 1918, Togusov et les principaux membres du Comité central furent arrêtés par le soviet d'Omsk. Sans être reconnus coupables, ils restèrent en prison où ils se trouvaient encore lorsque les Blancs reconquirent la région durant l'été 1918. Ils furent exécutés pendant l'hiver 1918-1919, mais dès la fin avril 1918, le parti Ǚ̌-žüz avait été de facto décapité.

La situation resta indécise jusqu'en mai 1918, cependant la tension monta progressivement entre Alaš orda et les soviets locaux. Les Cosaques avaient commencé à se soulever dès la fin du mois de mars dans l'Oural. Au cours des deux mois suivants, l'ensemble des stanitsas cosaques suivirent l'exemple. Les soviets se sentaient de plus en plus menacés et Alaš orda était de moins en moins enclin à un compromis avec eux d'autant plus qu'aucun signal clair ne fut donné par Moscou. La coopération entre Alaš orda et le pouvoir soviétique resta théorique. L'équilibre des forces fut renversé entre la fin mai et juin 1918, toutes les villes des deux oblasts orientaux tombant aux mains des Blancs ${ }^{98}$. Kulžanov, rare rescapé du parti Üš žüz, fut arrêté en juin 1918, puis fusillé au début de 1919. À Akmolinsk, Asylbekov et Sejfullin furent arrêtés par les Blancs et restèrent en prison jusqu'en 1919.

\section{L'oblast d'Ural'sk}

81 Début décembre 1917, Karataev, Argančeev et Ajtiev imitèrent la tentative du parti Üš žüz et en appelèrent au soviet d'Ural'sk pour remplacer le comité kazakh régional au motif que celui-ci refusait de reconnaitre le nouveau régime, mais le soviet, peu intéressé par les affaires kazakhes et circonspect quant aux convictions révolutionnaires du trio susnommé, se refusa à répondre. Il ne contrôlait pas la ville et était sous la menace du gouvernement cosaque d'Ural'sk, qui n'était pas encore décidé sur l'attitude à adopter vis-à-vis du soviet. Le danger représenté par les Cosaques et le manque de représentativité de ce groupe kazakh informel incitaient le soviet à la prudence. Le coup de force de Karataev, Argančeev et Ajtiev échoua et ils furent menacés d'arrestation par le comité kazakh.

82 Le pouvoir soviétique fut finalement instauré à Ural'sk le 18 janvier 1918, sans que les forces cosaques ne soient désarmées. L'équilibre était fragile et les uezds ne furent soviétisés que très partiellement entre la fin janvier et mars 1918. Le noyau des Kazakhs ayant rallié les soviets après la révolution d'Octobre s'investit dans la constitution de soviets kazakhs. Karataev, Ajtiev, Argančeev et Mendigerej Ipmagambetov furent ainsi à l'origine de l'apparition de soviets d'aul et de volost, essentiellement dans l'uezd d'Ural 'sk, dont ils étaient originaires à l'exception de Karataev. Fin mars 1918, le congrès des soviets de l'oblast d'Ural'sk élut un nouvel organe exécutif qui les intégra tous les quatre. Ajtiev, Argančeev et Mendigerej Ipmagambetov, plus sensibles aux idées socialistes, étaient devenus bolcheviks dans les mois précédents, mais Karataev, qui était membre du parti KD avant 1917, ne s'y résolut pas encore.

Ce noyau fut rejoint par un groupe dissident composé essentiellement de membres de la tribu bajuly, qui avait jusqu'alors soutenu le comité régional kazakh et Alaš orda. Les divergences n'étaient pas nouvelles, mais elles avaient été supplantées par le sentiment d'une nécessaire unité du mouvement national et par le carcan de la solidarité tribale. La veille de la prise d'Ural'sk par les soviets, le III ${ }^{e}$ Congrès régional kazakh se tint à Karatobe. Treize délégués formèrent un groupe, portant le nom d'Aq žol [la voie blanche], pour s'opposer à certaines des orientations adoptées ${ }^{99}$. Hormis la question de la réforme 
agraire toujours en suspens, le désaccord portait sur l'alliance possible avec le gouvernement cosaque d'Ural'sk et une taxation identique pour tous les Kazakhs afin de financer l'organisation d'une force armée kazakhe. Aq žol fut mené par Aliaskar Alibekov et comprenait notamment Selimgerej Karatleuov, Esengaly Kasabolatov, Aspandijar Kenžin, Nurgali Ipmagambetov et le fidèle compagnon d'Aliaskar Alibekov, Murzagaliev. Après avoir été mis en minorité, ces délégués décidèrent de se rapprocher des soviets, mais leur motivation ne relevait pas d'une adhésion aux idées soviétiques ou bolcheviques. Kasabolatov déclara ainsi en 1922 que «le groupe Aq žol était loin du bolchevisme et n'en avait même pas de claire perception. Il suivait des intérêts tribaux ( rodovye) ou personnels $»^{100}$. Ils étaient favorables à une orientation plus sociale et plus révolutionnaire que celle choisie par le congrès régional derrière les Dosmuhamedov et les élites tribales et pariaient plutôt sur les soviets dominés par les Russes que sur le gouvernement cosaque. Entre la fin janvier et mars 1918, il était impossible de deviner qui parviendrait à imposer son pouvoir dans l'oblast d'Ural'sk. Aucun ne fit d'ailleurs le choix de l'adhésion au parti bolchevik.

La situation évolua rapidement. Dès la fin mars 1918, le gouvernement cosaque reprit le contrôle de l'oblast et s'attaqua aux partisans des soviets. Aliaskar Alibekov et Murzagaliev furent brièvement arrêtés par les Cosaques pour leur participation au congrès régional des soviets. Karataev tomba dans les mains des Cosaques quelques jours après et fut incarcéré. Les autres membres kazakhs du soviet d'Ural'sk parvinrent à s'échapper et se réfugièrent dans leur aul. Courant avril, Žihanša et Halel Dosmuhamedov choisirent la voie de l'alliance avec les Cosaques afin de bénéficier de leur protection et d'obtenir des armes. Dès lors, ils s'émancipèrent du conseil national siégeant à Semipalatinsk et formèrent la branche occidentale d'Alaš orda ${ }^{101}$. La frontière entre les territoires sous l'autorité d'Alaš orda et ceux sous l'autorité de sa branche occidentale se calqua sur celle existant entre les žüz moyenne et cadette ${ }^{102}$.

\section{La Horde de Bukej}

La révolution d'Octobre eut un impact immédiat sur le paysage politique de l'ancienne Horde de Bukej. Un petit groupe bolchevik d'Astrahan', accompagné de Sejitkerej Nuralyhanov, töre étudiant à l'école des sous-officiers d'Astrahan' et sympathisant bolchevik, se rendit à Urda au tout début de décembre 1917. Le groupe s'appuya sur une centaine de Qaraqalpaq de l'aul $n^{\circ} 7$ de Bukej, qui formèrent une milice rouge ${ }^{103}$. Un meeting fut organisé le 2 décembre pour instaurer le régime soviétique. Sensibles à certaines idées socialistes, Mendešev, Musagaliev et Mendihanov s'y associèrent et participèrent ainsi à la formation d'un comité révolutionnaire ${ }^{104}$. Ils estimèrent qu'une alliance avec les soviets était le meilleur choix. Le coup de force eut lieu avant l'élection d'Alaš orda et fut facilité pour la partie kazakhe par l'absence de Kulmanov et de Tanašev, partis assister au II ${ }^{e}$ Congrès pankazakh. Un des éléments déclencheurs de cette fronde fut la prise de position de Kulmanov pour une alliance avec l'Union du Sud-Est des Cosaques, des montagnards du Caucase et des peuples libres des steppes. Si une collaboration avec les bolcheviks était impensable pour les membres du parti Alaš ou les Dosmuhamedov, un certain nombre d'intelligenty et de figures religieuses kazakhes ne pouvait pas plus envisager de rallier les Cosaques, associés au colonialisme tsariste.

Le comité révolutionnaire remplaça le comité régional kazakh qui fut dissout. Les Kazakhs, qui l'avaient intégré en décembre 1917, furent confortés lors du congrès 
régional des soviets au début mai 1918. Mendešev, Mendihanov, Musagaliev et Čumbalov entrèrent au nouveau soviet et furent nommés à des postes de responsabilité: Mendihanov obtint le commissariat à l'Intérieur, Mendešev devint vice-président du Comité exécutif régional, et Musagaliev, vice-commissaire à l'Éducation. Toutefois, aucun d'eux ne se décida à adhérer au parti bolchevik. Les sentiments nationaux et religieux prédominaient.

Le renforcement des positions soviétiques dans la région, qui fut favorisé par l'absence de stanitsas cosaques, incita d'autres personnalités à rejoindre les soviets. Ce fut le cas de Batyrhajyr Nijazov et de Šavkat Bekmuhamedov. Ce dernier avait participé aux congrès pankazakhs et au congrès panrusse des musulmans de mai 1917 et était le fils de Makaš Bekmuhamedov de la tribu bajuly, un des plus influents personnages de la Horde de Bukej. Gumar Karašev fit le même choix, pensant comme Musagaliev que son réformisme musulman était compatible avec les idéaux révolutionnaires. À la même époque, cette attitude fut partagée par de nombreux djadides ${ }^{105}$. À l'instar du premier noyau, ni Nijazov, ni Bekmuhamedov, ni Karašev n'adhérèrent au parti bolchevik. Toutes les tribus furent ainsi représentées dans le nouveau pouvoir soviétique à Bukej. Les élites tribales et religieuses avaient décidé de jouer la carte soviétique, en espérant préserver la spécificité de leur région.

\section{L'oblast de Turgaj}

Dans un premier temps, la révolution d'Octobre ne modifia pas l'équilibre politique kazakh dans l'oblast de Turgaj. À la tête de ses Cosaques, l'ataman Dutov avait empêché le soviet d'Orenburg de s'emparer de la ville et plus généralement de la région. Ce contexte fut mis à profit par Džangil'din qui rencontra Lenin en décembre 1917 pour préparer la conquête de l'oblast de Turgaj. Par suite de ces réunions, Džangil'din fut nommé commissaire provisoire pour l'oblast. Sa tâche était d'écarter Bukejhanov et de remplacer les comités kazakhs et les zemstvos par des soviets. Sa première mission était de créer des soviets au sein de la population kazakhe, afin d'envoyer dans un deuxième temps des délégués à Moscou pour préparer l'autonomie. Dans sa résolution sur la question nationale en mai 1917, le parti bolchevik « exigeait une autonomie régionale large [...] et une délimitation des frontières des oblasts autonomes réalisée par les populations locales, qui devaient tenir compte des conditions économiques et sociales et de la composition nationale ». Cette ligne politique avait été réaffirmée dans la déclaration des droits des peuples de Russie le 2 novembre 1917.

Dès sa nomination, Džangil'din rassembla un bataillon international sous son commandement, où il mobilisa des participants à la rébellion de 1916. Aux côtés des troupes rouges, ce bataillon participa activement au combat pour s'emparer d'Orenburg. Le 18 janvier 1918, la ville fut prise des mains des Cosaques de Dutov. Aussitôt, Džangil 'din chercha à constituer son équipe pour organiser les soviets dans l'oblast. Il s'entoura en premier lieu de ses proches: Amangel'dy Imanov et Bajkadam Karaldin. Puis, il s'adressa à l'intelligentsia et aux anciens fonctionnaires kazakhs pour leur proposer de travailler avec les soviets. Tungačin hésita à rejoindre le nouveau régime, dont les principes lui étaient étrangers ${ }^{106}$. Il demanda conseil aux siens et se décida à répondre favorablement à l'appel de Džangil'din afin de rentrer à nouveau dans le jeu politique. Parmi les principaux opposants au groupe de Bukejhanov, certains firent le pari soviétique. Ce fut le cas de Muhamedžan Seralin, que la déclaration de Lenin adressée aux 
musulmans de Russie et d'Orient le 20 novembre 1917 ne laissa certainement pas indifférent. Par contre, Sejdalin, rejetant l'idéologie soviétique, se retira de la politique. Plusieurs intelligenty kazakhs, impliqués dans le mouvement national en 1917, collaborèrent aussi avec les soviets. Durant les mois de mars et d'avril 1918, comme nous l'avons noté précédemment, Alaš orda fut en pourparlers avec le pouvoir soviétique, qui tentait de l'associer à son projet politique. La présence d'Esengaly Turmuhamedov parmi les nouveaux ralliés aux soviets est néanmoins étonnante, car il avait été le secrétaire de Bukejhanov et un des auteurs du programme du parti Alaš. Husajn Bekentaev, appartenant à un lignage qypšaq de l'uezd de Kustanaj et délégué au Deuxième Congrès pankazakh, intégra les organes soviétiques. En revanche, aucune figure notable de la tribu arghyn ne franchit le pas. Comme dans les autres oblasts, le choix du ralliement aux soviets ne releva pas généralement d'une adhésion au parti bolchevik. Džangil'din excepté, seuls Imanov et Tungačin s'y résolurent.

Džangil'din chargea les plus influents de ces intelligenty, qui l'avaient rejoint, d'organiser des soviets kazakhs dans les uezds pour y remplacer les comités kazakhs: Seralin dans l'uezd de Kustanaj, Amangel'dy Imanov dans celui de Turgaj, Tungačin dans celui d'Irgiz et Turmuhamedov dans celui d'Aktjubinsk. Il préparait activement le congrès régional des soviets de l'oblast de Turgaj et voulait que les Kazakhs y soient représentés. Le congrès se tint effectivement du 21 mars au 3 avril 1918. Les modalités d'éligibilité permettaient d'exclure directement les élites tribales, qui avaient été majoritairement représentées dans les comités kazakhs et dans Alaš orda: baj, anciens gouverneurs de volost, mollah,... Mais ces restrictions n'étaient pas appliquées de manière stricte lors des élections des délégués dans les uezds, ni même par la commission de vérification des mandats du congrès. Les exclusions résultaient de jeux de pouvoir. Dix députés kazakhs proches de Bukejhanov se trouvèrent ainsi exclus au motif d'être des éléments contre-révolutionnaires, mais le mandat d'Abdigapar Džanbosynov ne fut pas mis en doute. Le congrès élut un comité exécutif des soviets de l'oblast. La présidence fut donnée à Džangil'din et il inclut Tungačin et Husajn Bekentaev. Tous trois furent les premiers acteurs de la construction d'une représentation soviétique kazakhe. Au milieu du mois d'avril, Džangil'din repartit pour Moscou afin de défendre ses idées pour la soviétisation des steppes kazakhes.

\section{Troisième phase : la tentation blanche ou le début de l'expérience rouge}

91 Entre mars et juin 1918, le déclenchement de la guerre civile dans les régions peuplées de Kazakhs redistribua une fois de plus les cartes. Alaš orda et les comités kazakhs ne purent pas adopter la position d'une neutralité entre Rouges et Blancs. Ne possédant aucune force armée, le mouvement national kazakh dépendait du pouvoir en place. Alaš orda s'allia au Gouvernement provisoire sibérien dès la conquête par les Blancs de Semipalatinsk tandis que la branche occidentale d'Alaš orda, présidée par les Dosmuhamedov, s'associa officiellement au gouvernement cosaque d'Ural'sk le $1^{\text {er }}$ mai 1918. À l'été, les Blancs prirent le contrôle des oblasts de Semipalatinsk, d'Akmolinsk, d'Ural'sk et de Turgaj, à l'exception de quelques îlots ${ }^{107}$. Seul l'oblast de Bukej resta dans les mains des soviets. Dans les oblasts reconquis par les Blancs, les Kazakhs ralliés aux soviets durent faire face à la répression. Certains furent arrêtés, d'autres trouvèrent refuge dans leur aul respectif et furent protégés par leur lignage. Certains se 
rapprochèrent de partisans rouges et d'autres attendirent que la situation devienne plus favorable.

Un premier revirement accompagna ce changement de pouvoir : l'ancien secrétaire de Bukejhanov, Turmuhamedov, ou encore Aliaskar Alibekov et Murzagaliev rallièrent aussitôt Alaš orda ou sa branche occidentale. Durant l'été 1918, la plupart des membres du groupe Aq žol suivirent le même cheminement. Ils avaient refusé de s'allier aux Cosaques, mais l'émergence du comité des membres de l'Assemblée constituante à Samara (Komuč), qui était d'obédience socialiste, les incita à rejoindre le camp blanc ${ }^{108}$. Ce comité s'efforçait de fédérer les gouvernements blancs nés dans tout l'ancien empire et de créer une autorité russe légitime. Il s'était aussi clairement exprimé en faveur des autonomies nationales et reconnut Alaš orda. Plusieurs membres d'Aq žol choisirent de s'associer non à la branche occidentale d'Alaš orda, sous l'autorité des Dosmuhamedov, mais au bureau d'Alaš orda de l'oblast de Turgaj, dirigé par Dulatov et Bajtursunov avec lequel ils avaient plus d'affinités politiques.

Malgré un contexte défavorable, le pouvoir central soviétique n'abandonna pas pour autant son idée de créer des organes kazakhs. De retour à Moscou à la fin avril 1918, Džangil'din pilota la création du bureau kirghiz (kazakh) au sein du NKN. Après plusieurs réunions au NKN, Tungačin et Husajn Bekentaev furent nommés en mai pour occuper respectivement les postes de chef du bureau et d'adjoint ${ }^{109}$. Leur tâche première fut de développer un réseau de bureaux locaux dans les régions kazakhes afin d'inciter les Kazakhs à rejoindre les soviets et de préparer la future autonomie. En août 1918, Tungačin se rendit dans l'oblast de Bukej afin de transformer le seul territoire kazakh sous contrôle des soviets ${ }^{110}$ en fer de lance de la soviétisation des steppes. Comme l'indiquait Tungačin dans un rapport envoyé au Commissariat aux nationalités ${ }^{111}$ :

Étant donné l'impossibilité de traverser la ligne de front, nous avons dû limiter nos activités à la seule Horde de Bukej et, selon le déplacement du front et la reprise de villes et d'oblasts par les troupes soviétiques, [...] nous diffuserons et organiserons le pouvoir soviétique local et pour cela nous préparons des cadres dans notre bureau local. ${ }^{112}$

Les leaders kazakhs de Bukej se retrouvèrent dès lors impliqués dans la construction de l'autonomie soviétique, que les Kazakhs de l'oblast de Turgaj s'étaient auparavant appropriée.

95 Un deuxième congrès des soviets de l'oblast de Bukej fut organisé en septembre 1918. Il élut un comité exécutif régional qui confirma les anciens membres Kazakhs: Mendešev, Mendihanov et Musagaliev. Il intégra aussi des ralliés plus tardifs : Gumar Karašev, Šavkat Bekmuhamedov et Mustafa Kukebaev. Aucun de ceux-ci ne se décida encore à adhérer au parti bolchevik.

À cette époque, les communistes kazakhs étaient encore extrêmement minoritaires dans les steppes. Ils faisaient presque tous partie de l'équipe de Džangil'din ou du groupe d'Argančeev et d'Ajtiev. Les seconds vivaient dans la clandestinité, tandis que les premiers travaillaient à la constitution d'organes de représentation et d'administrations soviétiques proprement kazakhs. La création d'organes kazakhs du parti n'était pas leur principale préoccupation en 1918. En premier lieu, il s'agissait de préparer l'autonomie et de s'en assurer la direction. La participation aux institutions soviétiques n'était pas encore soumise à l'appartenance au parti bolchevik qui, compte tenu de son atrophie dans les steppes, ne pouvait aucunement constituer une base solide sur laquelle s'appuyer. 
Dans cette troisième phase, Džangil'din fut l'instigateur du ralliement aux soviets qui démontra de la manière la plus extrême le caractère déterminant du facteur tribal. En août 1918, il fut chargé d'organiser un bataillon expéditionnaire pour apporter armes, munitions et argent aux soldats de l'Armée rouge se battant au sud de l'oblast de Turgaj. Les troupes soviétiques y étaient totalement isolées, sans aucun ravitaillement. La mission était difficile et périlleuse, car il était nécessaire de faire un large détour, en passant par Astrahan', la mer Caspienne et la péninsule de Mangyšlak, où vivait la tribu adaj. Celle-ci, rattachée aux Bajuly de la žüz cadette, ne s'était pas impliquée dans les changements politiques, sans rejoindre ni Alaš orda, ni le pouvoir soviétique. Džangil'din, qui était accompagné de quelques Adaj ayant participé à la rébellion de 1916, prit contact avec un des plus influents personnages de la tribu: Tobonijaz Alnijazov, gouverneur de volost et un des chefs de la rébellion de 1916 dans sa région. Le 25 septembre, tous deux organisèrent une conférence qui rassemblait les 12 volosts adaj, et reconnut le pouvoir soviétique. Alnijazov y fut élu président du nouveau comité révolutionnaire de l'uezd. Le ralliement au nouveau régime fut le fait d'une décision du conseil tribal. Il ne comportait pas de motivations idéologiques et résultait de la persuasion dont avait su faire preuve Džangil'din. La question d'une adhésion au parti communiste ne s'était pas posée. Tout en combattant les incursions blanches dans l'uezd Adaj, Alnijazov continua à entretenir des relations avec la branche occidentale d'Alaš orda.

\section{Quatrième phase : nouveau mouvement de pendule}

Entre la fin de l'année 1918 et le début de 1919, l'Armée rouge mena une large offensive pour reprendre le contrôle d'Orenburg et d'Ural'sk. Les Kazakhs soviétiques participèrent activement aux combats qui se tinrent entre novembre 1918 et février 1919. La première brigade de cavalerie kazakhe, créée à Bukej sous la direction de Tungačin à l'automne 1918, participa à l'offensive dans l'oblast d'Ural'sk. Des cadres kazakhs, formés par le bureau local kazakh de l'oblast de Bukej, l'accompagnèrent pour aider à la constitution des soviets kazakhs dans les zones nouvellement reconquises. Par ailleurs, les Kazakhs arrêtés par les Blancs furent libérés ou purent sortir de la clandestinité après la prise de la ville d'Ural'sk. Ajtiev, Argančeev et Mendigerej Ipmagambetov réapparurent. Karataev sortit de prison et se résolut à adhérer au parti communiste. Au même moment, Aliaskar Alibekov, l'ancien leader d'Aq žol, et Murzagaliev se rendirent à Ural'sk pour rejoindre le camp des soviets et devinrent membres du parti communiste en mars, patronnés par Ajtiev et Argančeev. À Bukej, Mendešev, Bekmuhamedov, Karašev et Čumbalov firent aussi le choix de l'adhésion au parti. Cette décision s'explique en partie par la guerre civile, qui aviva les tensions politiques et qui poussait à des choix plus tranchés, mais aussi par le fait que le pouvoir bolchevik leur sembla ferme dans sa volonté d'accorder une autonomie politique aux Kazakhs.

Dans les oblasts orientaux, plusieurs Kazakhs furent aussi libérés. Ce fut notamment le cas de Sejfullin, d'Asylbekov et de deux anciens membres de l'Union démocratique de la jeunesse et du parti Üš žüz, Abulhair Dosov et Žanajdar Sadvokasov. Toutefois, leur région restait aux mains des Blancs. Asylbekov décida de rejoindre une unité de l'Armée rouge et partit combattre en Extrême-Orient. Il ne retourna dans les steppes kazakhes qu'en 1921. Les trois autres se réfugièrent dans leur aul et, au début de l'été 1919, rejoignirent des groupes de partisans rouges. Dosov et Sadvokasov adhérèrent alors au parti communiste. 
Džangil'din s'efforça à nouveau de préparer la convocation d'un congrès pankazakh des soviets. Il se préoccupa de réorganiser les soviets dans les uezds kazakhs suivant l'avancée du front. Un congrès de l'oblast d'Ural'sk fut organisé dès la fin du mois de février pour légitimer sa demande. Un «bureau pour les affaires kirghizes » y fut constitué sous la présidence de Karataev, secondé par Argančeev et Mendigerej Ipmagambetov. Ce même mois, Džangil'din et Tungačin se rendirent à Moscou pour demander l'accord des autorités centrales sur l'organisation du congrès pankazakh avec des représentants des régions de Bukej, d'Ural'sk et de Turgaj. Leur but était la proclamation d'une autonomie kazakhe le plus rapidement possible. Si Lenin et Stalin appuyaient la création de républiques autonomes, cette ligne politique était loin de faire l'unanimité au sein du parti communiste. Elle fut finalement entérinée lors du VIII ${ }^{e}$ Congrès du parti en mars 1919.

101 Ce débat sur les autonomies nationales n'était pas absent au sein du camp blanc, auquel s'était rallié Alaš orda. Ses membres étaient ainsi depuis décembre 1918 confrontés à un difficile dilemme, car le Gouvernement provisoire sibérien blanc s'était alors clairement opposé à toute forme d'autonomie, se réappropriant l'idéologie blanche originelle d'une Russie une et indivisible. Les Kazakhs blancs avaient dès lors commencé à discuter d'un changement d'alliance avec les leaders bachkirs, qui se trouvaient dans une situation analogue $^{113}$. La proclamation de la République autonome bachkire à la suite du VIII ${ }^{e}$ Congrès du parti et les victoires de l'Armée rouge sur tous les fronts incitèrent Alaš orda à tenter de négocier avec le pouvoir soviétique.

102 Les pourparlers furent menés par Ahmet Bajtursunov et Dulatov, les représentants d'Alaš orda dans l'oblast de Turgaj, De tous les leaders du Conseil national, Bajtursunov était le plus favorable à un rapprochement avec les soviets. Bukejhanov et les Dosmuhamedov ne l'envisageaient que comme un dernier recours. Le contact fut pris avec Bajkadam Karaldin, commissaire de l'uezd de Turgaj qui s'était engagé aux côtés des soviets sans adhérer au parti communiste. Ses positions modérées et son lien privilégié avec Amangel 'dy Imanov en faisaient l'intermédiaire idéal pour Bajtursunov. Une rencontre fut programmée entre les deux représentants d'Alaš orda, Karaldin, Imanov et Džangil'din afin de poser les bases d'un accord.

Le ralliement prochain d'Alaš orda fournissait un argument supplémentaire aux partisans de la convocation d'un congrès pankazakh. Džangil'din envoya aussitôt un radiogramme à Lenin, où il annonçait qu' " avait enfin commencé l'union de tout le peuple kirghiz des travailleurs derrière le drapeau rouge du gouvernement des ouvriers et des paysans $»^{114}$. S'appuyant sur la supposée reconnaissance du pouvoir soviétique par certains partisans d'Alaš orda, il demandait à Lenin des instructions pour la tenue prochaine d'un congrès pankazakh.

104 Toutefois, seul Bajtursunov participa à la rencontre, Dulatov était plus réticent à s'allier avec les soviets. Afin de concrétiser un accord entre Alaš orda et le pouvoir soviétique, Bajtursunov, Džangil'din et Karaldin partirent pour Moscou, où ils arrivèrent le $1^{\text {er }}$ avril. Profitant de ces négociations, Džangil'din et Tungačin réitérèrent leur demande de convoquer un congrès pankazakh et obtinrent satisfaction dans ce nouveau contexte politique et militaire. Après plusieurs mois d'offensives victorieuses, la situation sur le front semblait bien plus favorable aux Rouges au début du mois d'avril. Ainsi, le 4 avril 1919, le Comité exécutif central panrusse annonça la tenue prochaine d'un congrès constitutif de l'autonomie kazakhe à Orenburg et accorda une amnistie aux membres d'Alaš orda. 
Le processus de ralliement d'Alaš orda et la préparation du congrès pankazakh furent interrompus par une nouvelle offensive des forces blanches. Bajtursunov resta le seul membre important d'Alaš orda à avoir fait le pas en ce printemps 1919, sans toutefois adhérer au parti communiste. Il fut suivi par un petit groupe, composé essentiellement d'Arghyn et qui comprenait également Salimgerej Karatleuov et Aspandijar Kenžin, anciens du groupe Aq žol. À la suite des pourparlers, ce groupe proche de Bajtursunov intégra les troupes sous le commandement d'Imanov.

Ce ralliement de circonstance fut de courte durée sauf pour Bajtursunov. Les victoires des Blancs à la fin du printemps 1919 poussèrent les anciens d'Alaš orda à trahir leur nouvel allié. Imanov fut ainsi capturé et tué, alors qu'il devenait difficile de déterminer les orientations et les alliances politiques des différents acteurs. Après tous ces renversements de situation, de nombreux Kazakhs hésitaient sur le chemin à suivre. Le choix entre Rouges et Blancs, entre position modérée et plus radicale, était mêlé à l'impératif des solidarités tribales, toujours aussi essentielles. Par suite de cet événement, Karatleuov et Kenžin repartirent se cacher dans l'oblast d'Ural'sk. Nurgali Ipmagambetov, autre membre du groupe Aq žol, eut un parcours différent. Il resta aux côtés de la branche occidentale d'Alaš orda jusqu'en juin 1919. Son revirement prosoviétique fut provoqué par l'arrestation de son frère, Mendigerej, qui fut fusillé au mois de novembre. Nurgali parvint à se rendre à Ural'sk au début de l'hiver 1919 et adhéra aussitôt au parti communiste.

\section{Cinquième phase : le lancement de la soviétisation des steppes}

107 Le reflux des positions rouges dans les steppes et la rupture des négociations avec Alaš orda ne permettaient plus d'envisager une convocation prochaine du congrès pankazakh des soviets. Moscou, en accord avec les organes soviétiques kazakhs, décida de constituer un comité révolutionnaire kirghiz (Kirrevkom) pour assurer la transition institutionnelle avant le futur congrès constitutif de la République autonome kazakhe ${ }^{115}$. Ce comité bénéficiait de larges pouvoirs: il avait le droit d'amender toutes décisions des soviets locaux et avait autorité sur les oblasts de Turgaj, d'Ural'sk, de Semipalatinsk, d'Akmolinsk et de Bukej.

En juillet 1919, lors des discussions sur sa composition, les responsables du Commissariat aux nationalités avaient opté pour désigner un président kazakh, mais les délégués kazakhs avaient préféré s'abstenir de choisir un président dans leur rang, car les luttes d'influences se laissaient déjà pressentir ${ }^{116}$. Ils demandèrent donc que le pouvoir central nomme une personne "neutre» et expérimentée. Le choix se porta sur Stanislav Pestkovskij, vice-commissaire du NKN. Hormis ce dernier et Vadim Lukašev, vieux bolchevik, les autres membres étaient tous Kazakhs: Tungačin, Džangil'din, Bajtursunov, Karataev, Mendešev et Karaldin. Bajtursunov fut associé à la création du nouveau comité révolutionnaire et y fut nommé par Lenin, bien qu'il eût été écarté des discussions aux mois d'avril-mai par Tungačin et Džangil'din. Sa présence apparaissait primordiale aux leaders bolcheviks pour le succès de la soviétisation des steppes. En octobre 1919, Stalin écrivit ainsi dans une note: «Je ne le [Bajtursunov] croyais pas et je ne le crois toujours pas révolutionnaire communiste, ni même sympathisant, néanmoins sa présence au Kirrevkom est indispensable ${ }^{117}$. 
109 Durant cette période marquée par l'absence d'une organisation communiste kazakhe, l'adhésion au parti n'était pas un élément primordial. Le Kirrevkom était autonome dans ses décisions politiques par rapport aux organisations communistes locales à majorité russe. D'ailleurs, le pouvoir central refusa de répondre aux demandes de Tungačin de créer un bureau kazakh du parti, dont le rôle aurait été de déterminer la ligne politique du Kirrevkom. Moscou préféra jouer la carte de Bajtursunov, qui n'avait pas fait le choix de l'adhésion au parti, contre Tungačin, qui était communiste. Pestkovskij avait observé dès le mois de septembre que «nous voyons maintenant les conflits opposant certains leaders, [...] [reflétés dans] la guerre à demi déclarée entre les membres du Kirrevkom Bajtursunov et Tungačin [...] nous devons maintenant écarter le plus dangereux de ces escrocs (žulik) » $»^{118}$.

110 Tungačin fut progressivement écarté des postes de direction et fut envoyé en novembre 1919 à la représentation du Kirrevkom à Moscou. Puis, arrêté sur dénonciation de Lukašev, il fut envoyé dans une maison de repos (sanatorij) près de Moscou, où il séjourna dans la première moitié de $1920^{119}$. Oublié, il ne réapparut plus sur la scène politique kazakhe. Malgré leur collaboration depuis janvier 1918, Džangil'din ne soutint pas Tungačin. Étonnamment, Džangil'din resta en retrait de la direction politique même, pour se concentrer sur la soviétisation des régions kazakhes. Lui, qui avait rencontré Lenin et Stalin à plusieurs reprises, aurait logiquement dû être à la tête de l'autonomie naissante, dont il avait été l'un des principaux artisans. Auréolé du prestige de héros révolutionnaire, il préféra cependant se placer au-dessus des luttes de pouvoir, tout en restant présent dans les organes de direction.

111 Le rôle du Kirrevkom prit son sens avec la reconquête progressive des steppes kazakhes par l'Armée rouge dans la seconde moitié de 1919. Le ralliement aux soviets de nombreux Kazakhs accompagna cette avancée, mais il ne fut pas un mouvement massif et s'expliqua rarement par une adhésion au régime soviétique ou à l'idéologie communiste. Depuis le printemps 1918, les anciens membres du groupe Aq žol étaient passés plusieurs fois d'un camp à l'autre sans jamais trouver leur place. Aucun des deux, rouge ou blanc, ne répondait à leurs attentes. Les circonstances guidèrent leur choix, comme nous l'avons déjà montré. À la suite d'Aliaskar Alibekov, de Murzagaliev en février et de Nurgali Ipmagambetov en juin, Kasabolatov et Gubajdulla Alibekov optèrent pour les soviets en août 1919. Kenžin et Karatleuov tardèrent plus du fait de leur implication dans la mort d'Amangel'dy Imanov et rejoignirent les soviets entre décembre 1919 et janvier 1920. Ces démarches furent individuelles. À l'instar des trois premiers, Gubajdulla Alibekov, Kasabulatov, puis Kenžin et Karatleuov adhérèrent au parti communiste entre la fin de 1919 et le début de 1920 et tous furent aussi cooptés dans les comités révolutionnaires créés en attendant l'organisation des soviets locaux.

112 La branche occidentale d'Alaš orda fut approchée par le pouvoir soviétique à partir de la fin août 1919. Une lettre lui fut transmise dans laquelle transparaissaient les trois éléments centraux des discussions entre Alaš orda et les soviets, à savoir aide militaire, amnistie et statut du gouvernement autonome kazakh. Il y était noté :

Ayant proclamé le droit du peuple kirghiz (kazakh) à une existence indépendante et aidant par tous les moyens à la construction de la nouvelle vie, le gouvernement soviétique tente d'écarter toutes les entraves et est prêt à passer des accords avec tous les groupes politiques ou gouvernements existant sur le territoire kirghiz et composés de Kirghiz. C'est pourquoi nous nous adressons encore une fois à vous tous, proposant de mettre fin à la lutte contre nous, de nous aider contre les Cosaques et de commencer des négociations avec nous. 
Et d'ajouter :

nous sommes prêts à inclure dans le décret du SNK [Conseil des commissaires du peuple] sur l'amnistie tous les Kirghiz ayant reconnu leur culpabilité devant le pouvoir soviétique et à leur donner le droit de participer à la construction de leur nouveau pouvoir. ${ }^{120}$

Les leaders de la branche occidentale d'Alaš orda refusèrent de rallier les soviets, malgré l'évidence de la défaite militaire des Blancs. L'idéologie communiste leur était trop étrangère et ils n'avaient que mépris pour le radicalisme bolchevik. Ils n'avaient aucune confiance dans les promesses faites et ne pouvaient envisager de s'abaisser à rallier les soviets qu'ils avaient tant combattus. Moscou et le Kir-rev-kom réitérèrent leurs propositions à plusieurs reprises jusqu'au début 1920. Finalement, la branche occidentale d'Alaš orda fut dissoute en mars 1920 et ses principaux leaders furent exilés à Moscou et à Taškent, sans qu'aucun ne renie ses convictions. Dans la partie orientale, Alaš orda fut plus pragmatique, même si Bukejhanov et plusieurs autres leaders refusèrent tout ralliement politique. En décembre 1919, les membres d'Alaš orda, Halel Gabbasov, Žusipbek Ajmautov et Alimhan Ermekov, décidèrent d'entrer dans les nouvelles institutions soviétiques. Ils intégrèrent les comités révolutionnaires créés dans les oblasts d'Akmolinsk et de Semipalatinsk.

114 Le Kirrevkom et Moscou étaient d'accord sur la nécessité d'associer les anciens membres d'Alaš orda à la soviétisation, même s'il n'était pas question de leur accorder un poids politique dans les décisions. Le décret sur la dissolution d'Alaš orda indiquait clairement que «tous les collaborateurs [d'Alaš orda], considérés comme mobilisés, sont mis à la

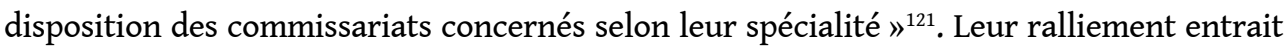
dans une politique plus large de «mobilisation des forces intellectuelles kirghizes». Le Kirrevkom devait en effet développer son activité dans l'ensemble du territoire qui lui avait été attribué et combattre les tendances centrifuges des administrations régionales majoritairement russes. Or, le comité révolutionnaire kirghiz peinait à recruter des « cadres » kazakhs, ses collaborateurs étant essentiellement russes. Sans Kazakhs dans les administrations soviétiques, l'autonomie ne pouvait être que fictive. De plus, les régions n'étaient que formellement sous le contrôle du pouvoir soviétique.

115 En janvier 1920, une conférence fut organisée à Aktjubinsk pour rassembler ces «forces intellectuelles kirghizes» derrière le pouvoir soviétique. Suivant les résolutions de la conférence, le Kirrevkom ordonna aux autorités locales de préparer des listes de noms des membres de l'intelligentsia kazakhe, indiquant leur spécialité et leur activité politique passée ${ }^{122}$. La seule exigence pour leur intégration était la reconnaissance du nouveau pouvoir. L'adhésion au parti communiste n'était en aucun cas une condition. La sélection restait très formelle, comme le démontre une directive du Bureau régional kirghiz du parti : «tenter de recruter tous les Kirghiz non communistes, mais honnêtes $»^{123}$.

116 Après plusieurs mois de discussions et de pressions, un bureau régional kazakh du parti communiste fut finalement constitué en mai 1920. Il accompagna le renforcement des communistes au sein du Kirrevkom. Si Bajtursunov en était devenu l'homme fort dans la seconde moitié de 1919, l'entrée de nouveaux membres originaires de l'oblast d'Ural'sk au début de l'année 1920 l'affaiblit, car ils avaient tous adhéré au parti communiste: Argančeev, Ajtiev et Aliaskar Alibekov. Ajtiev devint le nouveau leader du Kirrevkom. La composition du Bureau régional kazakh du parti marqua la prise du pouvoir par le groupe d'Ural'sk, avec quatre représentants sur les sept membres ${ }^{124}$. Toutefois, Karataev subit un sort analogue à celui de Tungačin. En conflit ouvert avec Bajtursunov, il fut renvoyé du 
Kirrevkom en mai 1920, puis arrêté deux mois plus tard sous l'accusation de corruption et d'abus de pouvoir. Relâché par la suite, il n'occupa plus aucun poste de responsabilité et finit par quitter le parti communiste en 1927.

117 La première tâche du Bureau régional kirghiz consistait à implanter le parti dans les steppes, où les organisations communistes kazakhes étaient très largement inexistantes. Des comités d'uezd, intégrant majoritairement des nouveaux adhérents kazakhs, furent alors confirmés par le Bureau régional kirghiz. En mai 1920, ce dernier décida d'imprimer de toute urgence 3000 cartes d'enregistrement pour cette campagne d'adhésion au parti communiste ${ }^{125}$. L'accroissement des membres du parti communiste en 1920 fut un phénomène général pour l'ensemble de la RSFSR, leur nombre ayant doublé entre 1919 et 1920. Le but en était d'accroître l'influence du parti sur les soviets locaux et de commencer à former de nouveaux cadres communistes. Dans un article de Žizn' nacional 'nostej intitulé « La Kirghizie autonome », l'auteur insistait sur les avancées du «travail de préparation de nouveaux cadres-travailleurs kirghiz qui seront les pionniers des principes soviétiques $»^{126}$.

Bajtursunov, qui avait saisi l'importance du changement opéré avec la création du Bureau régional kazakh, adhéra aussitôt au parti communiste. Il incita les anciens membres d'Alaš orda à le suivre pour pouvoir être capable de peser sur les orientations politiques et écrivit même une lettre ouverte en ce sens ${ }^{127}$. Il échoua cependant à promouvoir sa stratégie parmi ses compagnons et seul Žusipbek Ajmautov répondit à son appel. Progressivement, ceux qui ne rejoignirent pas le parti communiste furent écartés des postes de responsabilité au niveau du Kirrevkom. Il n'y avait toutefois aucune restriction à l'adhésion entre 1919 et 1920. Malgré cela, nombreux furent ceux qui s'y refusèrent, dont Karaldin qui, de fait, ne fut pas inclus dans la nouvelle mouture du Kirrevkom en août 1920. Il repartit dans son uezd de Turgaj, où il présida le comité révolutionnaire. D'autres se retirèrent de toutes activités politiques.

119 Bajtursunov se maintint au Kirrevkom, obtenant le renfort d'un ancien d'Alaš orda, Alimhan Ermekov, coopté en août, mais les Kazakhs originaires des oblasts d'Ural'sk et de Bukej continuèrent à dominer le Kirrevkom et le Bureau régional du parti jusqu'à la convocation du congrès constitutif de la République autonome kazakhe en octobre 1920. Au-delà des dissensions, un consensus existait entre toutes les factions autour de la nécessité d'une autonomie nationale et d'une délimitation territoriale large. Lors des discussions à Moscou pendant l'été 1920, tous défendirent l'attribution d'un territoire correspondant aux revendications du second congrès pankazakh de décembre $1917^{128}$.

\section{Conclusion}

120 Alibi Džangil'din a inauguré notre intrusion dans la révolution kazakhe. Il n'adhéra pas au parti bolchevik par suite de sa participation à un mouvement ou à des événements révolutionnaires, il le rejoignit dans sa quête d'une voie vers la transformation de la société reposant sur la justice sociale, l'égalité et la démocratie. Contrairement à la majorité des autres Kazakhs, il fut attiré par la voie radicale des bolcheviks. Absents des soviets et des partis révolutionnaires dans la première moitié de 1917, certains Kazakhs choisirent de s'en rapprocher. Au-delà de la radicalisation générale en Russie et du désaveu $d u$ Gouvernement provisoire, leur motivation fut au moins triple: une sensibilisation aux slogans révolutionnaires; la déception face aux orientations choisies par le mouvement national kazakh; leur marginalisation au cours des congrès de 1917. 
Enfin, la dépendance des Kazakhs à l'égard de la Russie, qui supposait la reconnaissance par un pouvoir russe des organes nationaux kazakhs, joua un rôle prépondérant. Dans la période d'affrontement entre Blancs et Rouges, le choix de l'allié se fondait sur des conjectures à la fois pragmatiques et idéologiques. Les hésitations furent nombreuses, car personne ne pouvait connaître ni le futur vainqueur de la guerre civile ni ses intentions quant à l'autonomie kazakhe.

Après février 1917, des groupes se formèrent pour construire le mouvement national kazakh. Leur constitution reposa sur des réseaux déjà existants, avec l'appartenance tribale pour principal élément fédérateur. La solidarité tribale se plaçait au cœur du jeu politique. Les tribus les plus puissantes s'arrogèrent le contrôle du mouvement national. Ce fut le cas des Arghyn dans les oblasts de Turgaj, d'Akmolinsk et de Semipalatinsk et des Bajuly dans l'oblast d'Ural'sk et dans la Horde de Bukej. Ainsi, en suivant un raccourci analytique, il est possible de définir les Kazakhs ayant rallié le pouvoir soviétique entre 1917 et 1918 comme ceux ayant été mis à l'écart des congrès et des différents comités kazakhs. Cette constatation permet de saisir le caractère hétéroclite de ces intelligenty, qui appartenaient à des tribus et des lignages plus faibles ou plus en retrait du mouvement national : žetìru, qypšaq, kerej, najman, tölenggit, qaraqalpaq. Les töre y furent aussi très représentés, car la préséance politique mentionnée précédemment dépendait largement du soutien des élites tribales ou, autrement dit, de la reconnaissance de leur autorité par des lignages. Dans le contexte révolutionnaire, le principe démocratique et la mainmise sur le mouvement national des deux principales tribus, arghyn et älìmuly, affaiblirent les töre qui n'étaient pas parvenus à s'attacher leur soutien. Ce processus de diminution de l'influence politique des töre avait été initié par le pouvoir tsariste au $\mathrm{XIX}^{\mathrm{e}}$ siècle $^{129}$. Au moment de la création de la république autonome en octobre 1920, les töre, Bukejhanov, Karataev et Tungačin, qui avaient été au cœur du débat politique, avaient déjà été relégués au second plan et n'y prirent aucunement part ${ }^{130}$. La préséance politique des töre fut dès lors définitivement abolie.

Ces constats ne signifient pas que la vie politique kazakhe était réduite à des rapports de forces entre tribus. L'aura de certaines personnalités dépassait largement le clivage tribal et reposait sur une pensée et un projet politiques. Les réflexions sur la nation kazakhe au sein de l'intelligentsia poussaient à une remise en question des pratiques politiques liées à la structure tribale de la société kazakhe, mais, en 1917, l'espace politique kazakh n'avait jamais pu se constituer au-delà du volost ou de l'uezd. Le rôle des lignages y était central.

Parmi ces premiers Kazakhs à rejoindre les soviets, il est possible de distinguer deux groupes. L'un, présent dans l'oblast d'Ural'sk autour d'Argančeev et dans l'oblast de Turgaj autour de Džangil'din, opta pour une adhésion au parti bolchevik. L'autre, présent surtout dans la Horde de Bukej et dans l'oblast d'Akmolinsk, choisit de rester en dehors du parti. Les deux groupes partageaient le principe de la justice sociale et l'idée de la nécessité d'une sédentarisation des Kazakhs, qui avait été défendue notamment par Karataev et Imanov. La principale différence s'exprime dans le regard porté sur l'islam. Hormis une orientation moins radicale, le second groupe se caractérisait en effet par la prédominance d'un courant religieux. Son projet était une islamisation de la société kazakhe au travers des réformes promues par le djadidisme. Ce courant ne se retrouva pas dans la ligne du mouvement national kazakh, qui lui apparaissait trop proche du libéralisme russe. Par ailleurs, les Blancs, que rallièrent Alaš Orda et sa branche occidentale, étaient associés à la politique tsariste de christianisation et de russification. 
Les Rouges introduisaient des changements de paradigmes, dans lesquels le courant djadide kazakh chercha des éléments de convergence.

L'intégration des Kazakhs dans les soviets ne témoignait pas d'une réelle reconnaissance par le nouveau régime de leur participation politique à la révolution, mais la place laissée vacante par le Conseil national Alaš orda, qui refusait de collaborer avec les soviets, ouvrit la voie à tous ceux qui avaient été marginalisés au cours de l'année 1917. L'alliance de la branche occidentale d'Alaš orda avec les Cosaques, puis le refus en décembre 1918 d'accorder toute autonomie nationale par le gouvernement sibérien, allié d'Alaš orda, provoquèrent des tensions au sein du mouvement national. Les victoires rouges les incitèrent à rallier les soviets, mais les défaites les faisaient changer de camp. Ce mouvement de pendule dura jusqu'à la fin de 1919 et la dissolution d'Alaš orda. Si Bajtursunov fit le pari soviétique en 1919, puis bolchevik en 1920, il ne fut suivi par aucun des principaux leaders d'Alaš orda, qui restèrent fidèles à leurs convictions.

Une aspiration commune à l'ensemble des acteurs demeurait la proclamation de l'autonomie kazakhe sur les territoires peuplés de Kazakhs. La création du comité révolutionnaire kazakh ou Kirrevkom avait pour ambition de la réaliser. Il réunit les différents groupes ayant rallié les soviets : ceux de Turgaj, d'Ural'sk, de Bukej et enfin Bajtursunov. Džangil'din adopta une position de retrait relatif et le groupe de Turgaj en fut affaibli. La formation d'un bureau régional kazakh du parti communiste renforça la position du groupe d'Ural'sk, dont plusieurs membres avaient adhéré au parti dès 1918. Le groupe de Bukej ne fit ce choix qu'en 1919 et Bajtursunov en 1920.

L'année 1920 lança la soviétisation des steppes et l'entrée plus massive des Kazakhs au parti communiste. Une nouvelle période s'ouvrit avec la proclamation de la République autonome kazakhe en octobre 1920. La primauté politique donnée au parti communiste et les réformes soviétiques initièrent une nouvelle phase de transformations des structures politiques kazakhes, dans laquelle la référence tribale était censée disparaître.

\section{Liste des noms et appartenance tribale}

- Ajmautov Žusipbek (1889-1931) [žüz moyenne, tribu arghyn]

- Ajtiev Abdrahman (1886-1936) [žüz cadette, tribu žetìru]

- Ajtbakin Amre (1859-1919) [žüz moyenne, tribu arghyn]

- Ajtpenov Mukan (?-1937) [žüz moyenne, tribu kerej]

- Akpaev Žakyp (1876-1934) [žüz moyenne, tribu arghyn]

- Alibekov Aliaskar (1893-1937) [žüz cadette, tribu bajuly]

- Alibekov Gubajdulla (1870-1923) [žüz cadette, tribu bajuly]

- Alnijazov Tobonijaz (1875-1930) [žüz cadette, tribu bajuly/adaj]

- Alžanov Šajmerden (? - 1918) [žüz moyenne, tribu kerej]

- Argančeev Sakipgerej (1887-1938) [žüz cadette, tölenggitt]

- Asylbekov Abdolla (1896-1938) [žüz moyenne, tribu arghyn]

- Bajtursunov Ahmet (1873-1938) [žüz moyenne, tribu arghyn]

- Bekentaev Husajn (1896- ?) [žüz moyenne, tribu qypšaq]

- Bekmuhamedov Makaš (1830-1904) [žüz cadette, tribu bajuly]

- Bekmuhamedov Šavkat (1892-1958) [žüz cadette, tribu bajuly]

- Bukejhanov Alihan (1866-1937) [töre, lignage du khan Barak]

- Čumbalov Mažit (1873-1940) [žüz cadette, tribu noghaj]

- Dosmuhamedov Halel (1883-1939) [žüz cadette, tribu bajuly] 
- Dosmuhamedov Žihanša (1885-1938) [žüz cadette, tribu bajuly]

- Dosov Abulhair (1899-1938) [žüz moyenne, tribu kerej]

- Dulatov Miržakup (1885-1935) [žüz moyenne, tribu arghyn]

- Džangil'din Alibi (1884-1953) [žüz moyenne, tribu qypšaq]

- Ermekov Alimhan (1891-1970) [žüz moyenne, tribu arghyn]

- Gabbasov Halel (1888-1931) [žüz moyenne, tribu arghyn]

- Imanov Amangel'dy (1873-1919) [žüz moyenne, tribu qypšaq]

- Ipmagambetov Mendigerej (1875-1919) [žüz cadette, tribu qaraqalpaq]

- Ipmagambetov Nurgali (1883-1922) [žüz cadette, tribu qaraqalpaq]

- Kabekov Ishak (1892-1918) [žüz moyenne, tribu najman]

- Kalmenov Alpysbaj (1869-1937) [žüz cadette, tribu bajuly]

- Karaldin Bajkadam [žüz moyenne, tribu qypšaq]

- Karašev Gumar (1875-1921) [žüz cadette, tribu noghaj]

- Karataev Bahytžan (1863-1934) [töre, lignage de Nuraly fils d'Abulhair]

- Karatleuov Selimgerej (1887-1938) [žüz cadette, tribu bajuly]

- Kasabolatov Esengaly (1889-1938) [žüz cadette, tribu bajuly]

- Kenžin Aspandijar (1887-1938) [žüz cadette, tribu bajuly]

- Kukebaev Mustafa (1888-1964) [žüz cadette]

- Kulmanov Bahtygerej (1857-1919) [töre, lignage de Nuraly fils d'Abulhair]

- Kulžanov Nurgali (1869-1919) [žüz moyenne, tribu arghyn]

- Kusepkaliev Dauletšah (1870-1944) [töre, lignage de Nuraly fils d'Abulhair]

- Mendešev Sejtkali (1882-1937) [žüz cadette, tölenggìt]

- Mendihanov Išangali (1872-1919) [žüz cadette, tölenggìt]

- Munajtpasov Hadžimukan [žüz moyenne, tribu qypšaq]

- Murzagaliev Muhamedhafij (1887-1941) [žüz cadette, tribu žetìru]

- Musagaliev Gabdulgaziz (1880-1933) [töre, lignage de Nuraly fils d'Abulhair]

- Nijazov Batyrhajyr (1872-1921) [žüz cadette, tribu noghaj]

- Nuralyhanov Sejitkerej [töre, lignage de Nuraly fils d'Abulhair]

- Omarov Salyk (?-1941) [žüz cadette, tribu bajuly]

- Sadvokasov Žanajdar (1898-1938) [žüz moyenne, tribu kerej]

- Sejdalin Žihanša (1877-1923) [töre, lignage de Nuraly fils d'Abulhair]

- Sejfullin Saken (1894-1938) [žüz moyenne, tribu arghyn]

- Seralin Muhamedžan (1872-1929) [qoža]

- Tanašev Vali (1887-1968) [žüz cadette, tribu bajuly]

- Temirov Abdulla (1865- ?) [žüz cadette, tribu älìmuly]

- Togusov Kol'baj (1879-1919) [žüz moyenne, tribu najman]

- Togusov Sulejman [žüz moyenne, tribu najman]

- Tungačin Muhamed'jar (1888-1942) [töre, lignage d'Ajčuvak fils d'Abulhair]

- Turlybaev Ajdarhan (1877-1937) [žüz moyenne, tribu arghyn]

- Turmuhamedov Esengaly [žüz cadette]

- Žanajdarov Sejlbek (1884-1929) [žüz moyenne, tribu arghyn] 


\section{NOTES}

1. AP RK (Arhiv Prezidenta Respubliki Kazahstan - Archives du Président de la république du Kazakhstan), 141/1/488g/31 : le chiffre donné pour 1921 comprend les communistes kazakhs de la République autonome kazakhe et donc exclut ceux du Turkestan.

2. Il s'agit de Sakipgerej Argančeev. Il put y avoir d'autres cas isolés de Kazakhs ayant rejoint sur de courtes périodes des cellules locales de partis révolutionnaires, mais ces adhésions restèrent de très rares exceptions. Des organisations SR et SD russes étaient apparues en 1905 dans différentes villes de la région des steppes, mais elles furent pour la majorité dissoute dans les deux ou trois années suivantes, du fait de la répression.

3. Les publications de références pour le contexte général sont : M.K. Qojgeldiev, Alaš qozghalysy [La révolte d'Alaš], Almaty : Sanat, 1995 ; D.A. Amanžolova, Kazahskij avtonomizm i Rossija [L'autonomisme kazakh et la Russie], M. : Rossija molodaja, 1994 ; Xavier Hallez, « Du statut d'allogène à celui de citoyen soviétique : La route des Kazakhs vers une autonomie politique 1905-1920 », Cahiers d'Asie centrale, IFEAC, 23, 2014.

4. S. Zimanov, S. Dauletova, M. Ismagulov, Kazahskij otdel Narodnogo Komissariata po delam nacional'nostej RSFSR [Le bureau kazakh du Commissariat aux nationalités de la RSFSR], Alma-Ata : Nauka, 1975 ; S.Zimanov, S. Dauletova, M. Ismagulov, Kazahskij revoljucionnij komitet [Le Comité révolutionnaire kazakh], Alma-Ata : Nauka, 1981; K.N. Nurpejsov, Stanovlenie sovetov v Kazahstane (mart 1917g.-ijun' 1918g.) [La constitution des soviets au Kazakhstan (mars 1917-juin 1918)], Alma-Ata : Nauka ; T.E. Eleuov, Ustanovlenie i upročenie Sovetskoj vlasti $\mathrm{v}$ Kazahstane [La mise en place et le renforcement du pouvoir soviétique au Kazakhstan], Alma-Ata : Nauka ", 1961.

5. K. Bejsembiev, Idejno-političeskie tečenija $\mathrm{v}$ Kazahstane konca XIX-načala XX veka [Les tendances politiques et des idées au Kazakhstan, fin du XIX ${ }^{\mathrm{e}}$-début du Xxe siècle), Alma-Ata : Izdat. AN KazSSR, 1961, p. 42-50.

6. Marco Buttino, La rivoluzione capovolta : l'Asia centrale tra il crollo dell'Impero zarista e la formazione dell'URSS, Naples : L'ancora del mediterraneo, 2003 ; Tomohiko Uyama, " Two attempts at Building a Qazaq State: The revolt of 1916 and the Alash Movement ", in S. Dudoignon et Hisao Komatsu, eds., Islam in Politics in Russia and Central Asia (Early Eighteenth to late Twentieth Centuries), Londres : Paul Kegan, 2001, p. 77-97.

7. Tomohiko Uyama, "The Geography of Civilizations : A Spatial Analysis of the Kazakh Intelligentsia's Activities, from the Mid-Nineteenth to the Early Twentieth Century », Kimitaka Matsuzato, ed., Regions : A Prism to View the Slavic-Eurasian World: Towards a Discipline of "Regionology", Sapporo : Slavic Research Center, Hokkaido University, March 2000, p. 70-99.

8. Xavier Hallez, « Le rôle des relations tribales dans la constitution des mouvements politiques kazakhs entre 1905 et 1918 ", in Anne Ducloux, Svetlana Gorshenina, Anna Jarry-Omarova, dir., Anthropologie des réseaux en Asie centrale, P. : CNRS éditions, 2012, p. 89-114.

9. Voir plus bas la liste de tous les noms cités dans le corps du texte avec leur appartenance tribale.

10. La žüz aînée nomadisait essentiellement dans les oblasts du Semireč’e et du Syr-Darya , la žüz moyenne dans les oblasts d'Akmolinsk et de Semipalatinsk, dans les uezds de Kustanaj et de Turgaj de l'oblast de Turgaj et dans la partie septentrionale des oblasts du Semireč'e et du Syr-Darya et la žüz cadette dans l'oblast d'Ural'sk, dans la horde de Bukej, dans les uezds d'Aktjubinsk et d'Irgiz de l'oblast de Turgaj, dans l'uezd de Mangyšlak de l'oblast de Transcaspienne et au nord de l'oblast du Syr-Darya. Pour une description détaillée de la 
localisation des tribus dans chaque uezd au début $d u x^{e}$ siècle, voir Marat Muqanov, Qazaq žerìnìng tarihy [Histoire de la terre kazakhe], Almaty : Atamura, 1994.

11. Royal Anthropological Institution, Notes and Queries in Anthropology, Londres : Routledge and Paul Kegan, 1967, p. 88-89.

12. Nurbulat Masanov, Kočevaja civilizacija Kazahov: osnovy žiznedejatel'nosti nomadnogo obščestva [La civilisation nomade des Kazakhs. Les fondements de la vie sociale des nomades], Almaty : Print-S, 2011, p. 398.

13. L'emploi du terme « kirghiz » en italique réfère à son utilisation dans les sources russes avant 1925, il renvoie à la fois aux Kazakhs et aux Kirghiz. Dans cet article, il correspond avant tout aux Kazakhs. Ibid., p. 400.

14. Masanov, Kočevaja civilizacija Kazahov, p. 403.

15. I.V. Erofeeva, Rodoslovnye kazahskih hanov i koža. XVIII-XIXvv. [Généalogies des khans et qoža kazakhs], Almaty : Print-S, 2003, p. 17-18.

16. Pour une étude du parcours d'un communiste kazakh ayant occupé les plus hautes fonctions dans le Turkestan soviétique à la même période cf. Xavier Hallez, « Turar Ryskulov : the career of a Kazakh revolutionary leader during the construction of the new soviet state, 1917-1926», Colloquia Humanistica, Institute of Slavic Studies of the Polish Academy of Sciences, 3, 2014.

17. Les Kazakhs furent autorisés à élire un député dans chaque oblast aux deux Premières Dumas d'État. Le gouvernement tsariste supprima ce droit pour les élections suivantes.

18. Les noms propres kazakhs sont retranscrits depuis le russe, à l'exception des tribus et des références bibliographiques kazakhes.

19. Cf. E.J. Hobsbawm, Les bandits, P. : Petite collection Maspero, 1972. « Le banditisme intervient plus souvent dans les révolutions paysannes simplement comme un des aspects multiples de la mobilisation, [...] celui des combattants et des chefs de guerre qu'il fournit " (p. 100). « Le bandit social est un paysan hors-la-loi que le seigneur et l'État considèrent comme criminel, mais qui demeure à l'intérieur de la société paysanne, laquelle voit en lui un héros, un champion, un vengeur, un justicier, peut-être même un libérateur » (p. 8) « Ces hommes sont ceux qui, en face de l'injustice ou d'une forme de persécution, refusent de se soumettre docilement à la force» (p. 26). Vengeur " quand un nouvel État procède à des interventions qui heurtent les usages locaux ou donne son appui à celle des familles rivales qui possède le plus d'influence» (p. 62).

20. Personne s'étant illustrée par des actes héroïques et aussi statut de celui qui doit défendre son lignage.

21. Les barymtašy étaient des Kazakhs qui, ayant pratiqué plusieurs barymta [vol de bétail] avec succès, étaient devenus maîtres dans cet art. La barymta était une pratique qui s'ancrait dans les règlements des conflits entre les lignages ou entre les tribus. Sur la transformation de la perception de leur rôle social à la période coloniale : Virginia Martin, «Barïmta : Nomadic custom, imperial crime » in Daniel R. Brower, Edward J. Lazzerini, eds., Russia's Orient : Imperial borderlands an peoples, 1700-1917, Bloomington : Indiana UP, 1997, p. 249-270.

22. Le journal Qazaq fut publié de février 1913 à septembre 1918, mais un autre journal, Ajqap, eut aussi une diffusion « nationale » de 1911 à 1915.

23. Uezd d'Irgiz : Abdolla Temirov ; uezd de Turgaj : Omar Almasov ; uezd d'Aktjubinsk : Myco (Allemand) ; uezd de Kustanaj : Ahmet Birimžanov.

24. Alihan Bukejhanov, "Vybory v stepi [Élections dans la steppe]», K 10-letiju Pervoj Gosudarstvennoj Dumy [Pour les dix ans de la Première Duma d'État], SPb.: Ogni, 1916, in R. Nurgaliev, red., Ä.Bökejhan. Tangdamaly(Izbrannoe) [A.Bukejhanov. CEuvres choisies], Almaty : Qazaq Ènciklopedijasy, 1995, p. 403.

25. CGA RK (Central'nyj Gosudarstvennyj Arhiv Respubliki Kazahstan - Archives centrales d'État de la république du Kazakhstan) : 1023/1/6/3. 
26. Karaldin participa à la construction de plusieurs barrages et de canaux d'irrigation dans la première décennie du $\mathrm{Xx}^{\mathrm{e}}$ siècle. En 1902, il publia aussi un article sur l'agriculture irriguée dans Turgajskaja gazeta [le journal de Turgaj]. Künimžan Bajqadamova, Bajqadamovtar äuletì derektì hikajat [Documents sur la lignée Bajkadam], Almaty : Bilim, 2009.

27. Älìbì Žankeldìn [Alibi Džangil'din], Dokumentter men materialdar [Documents], Almaty : Qazaqstan, 1975, p. 13

28. Benedict Anderson, Les Bannières de la révolte, P. : La Découverte, 2009.

29. Population turkophone de confession juive présente surtout en Crimée et en Lituanie.

30. Vladimir Poljakov, Do menja. Krym- Rodina, familija, sud'ba (Memuary) [Avant moi, la Crimée. Ma patrie, ma famille, un destin. (Mémoires)], http://www.historians.in.ua/index.php/ en/istoriya-i-pamyat-vazhki-pitannya/710-vladymyr-poliakov-do-menia-krym--rodyna-famylyia -sudba-memuary-2004-2012-chast-3. Dernier accès le 28 janvier 2016.

31. Ä. Žankeldìn [A. Džangil'din] « Menìng žolym » [mon chemin], in Žankeldìn, Dokumentter men materialdar, p. 21-22

32. Iman batyr (1780-1847) descendait d'un lignage de batyr qui avaient combattu les Djoungars. Il soutint la rébellion de Kenesary et intégra son conseil rapproché. Il l'accompagna dans sa retraite vers le sud et fut tué à ses côtés non loin de l'actuelle ville de Tokmak au Kirghizistan.

33. Kenesary Kasymov (1802-1847), petit-fils du khan Abylaj, dirigea une rébellion contre le pouvoir russe entre 1837 et 1847 . Il chercha vainement à unir les trois žüz pour rétablir un khanat kazakh. Il fut finalement contraint à quitter ses pâturages, situés entre les futurs oblasts de Turgaj et d'Akmolinsk, pour se réfugier sur les terres kirghizes où il trouva la mort. Sa mémoire continue d'être célébrée.

34. Amangel'dy Imanov, Stat'i, dokumenty i materialy [Articles et documents], Alma-Ata : Kazahstan, 1973 ; A. Nurkanov, Amangel'dy Imanov, Alma-Ata : KazGosIzdat., 1959. Ce dernier livre s'appuie sur les documents et les interviews collectés en 1943 par une expédition de la filiale kazakhe de l'Académie des sciences consacrée à Amangel'dy Imanov.

35. Le terme de džigit désigne un jeune homme et par extension un soldat.

36. Cf. Amengeldinskaja èkspedicija Kaz. Filiala AN SSSR [L'expédition Amangel'dy de la filiale kazakhe de l'Académie des sciences de l'URSS], 1943.

37. M. Myrzaghaliuly, 1916-1917 žyldardaghy Torghaj Qazaqtarynyng köterìlìsì [La rébellion des Kazakhs de Turgaj dans les années 1916-1917], Almaty, 2005.

38. D’après certaines sources, Džanbosynov aurait été élu khan par 6 lignages qypšaq, 6 lignages arghyn et 1 lignage najman. Au XIX siècle, Qypšaq et Arghyn s'étaient rassemblés sous la bannière de Kenesary Kasymov dans la région de Turgaj. Les Qypšaq avaient néanmoins représentés la principale force. En 1916, les lignages arghyn entrés en rébellion acceptèrent l'autorité de Džanbosynov, mais ils restèrent autonomes et se désengagèrent progressivement. Myrzaghaliuly, 1916-1917 žyldardaghy Torghaj Qazaqtarynyng köterìlìì̀, p. 42

39. Bajtursunov, Dulatov, Kadirbaev, M. Tungačin, « Torghaj Häm Yrghyz halqyna » [À la population de Turgaj et d'Irgiz], Qazaq, n² 207, 1916, Ä. Nysanbaev, red., Qazaq gazetì, Qazaq Ènciklopedijasy, Almaty, 1998, p. 348-349.

40. Après le début de la mobilisation en septembre 1916, Bukejhanov rencontra le prince L'vov, président de l'Union des zemstvos et futur chef du Gouvernement provisoire russe, pour le convaincre d'ouvrir des bureaux pour les allogènes dans les villes du front ouest. À partir du mois d'octobre 1916, ces bureaux, qui devaient aider et soutenir les Kazakhs mobilisés, furent constitués auprès des zemstvos dans plusieurs villes occidentales de l'Empire, le plus important se trouvant à Minsk.

41. Les zemstvos étaient des organes élus de gestion locale accordés par le tsar en 1864. La Sibérie, puis les deux gouvernorats des steppes et du Turkestan ne bénéficièrent pas de la réforme. La création de zemstvos fut une des revendications des allogènes jusqu'en 1917, lorsque 
ce droit leur fut finalement accordé. Le droit électoral y était limité aux propriétaires terriens, aux marchands et aux entrepreneurs.

42. Džangil'din se convertit effectivement à l'orthodoxie en 1898 et reçut le nom de Nikolaj Stepnov. « Islam dìnìne qajtu [retour à la religion musulmane] », Qazaq, n 170, 1916.

43. Žankeldìn, Dokumentter men materialdar, p. 72.

44. A.A. Bisembaev, Istorija Aktjubinskoj oblasti [Histoire de l'oblast d'Aktjubinsk], Aktöbe : Oblastnoj Centr istorii, ètnografii i arheologii, 2006, p. 337-338.

45. M.K. Kozybaev, P.M. Pahmurnyj, eds., Amangel'dy Imanov (stat'i, dokumenty, materialy) [Amangel'dy Imanov, articles et documents)], Alma-Ata : Kazahstan, 1974, p. 85-86.

46. « Älì Žankeldìn ", Qazaq, n 237, 24/07/1917, Nysanbaev, réd., Qazaq gazetì, p. 403.

47. « Pis'mo k Orenburgskom Sovete rabočih, soldatov i krest'jan [Lettre au soviet des ouvriers, des soldats et des paysans d'Orenburg] », Zarja, n 125, 18/09/1917, in Žankeldìn, Dokumentter men materialdar, p. 73.

48. Karaldin organisa une assemblée d'aqsaqal (les anciens à la fois juges et conseillers) des deux tribus pour apaiser la situation. Bajqadamova, Bajqadamovtar äuletì derekti hikajat, p. 36.

49. « Pis'mo k Orenburgskom Sovete rabočih, soldatov i krest'jan », p. 73.

50. Žankeldìn, Dokumentter men materialdar, p. 74.

51. Les documents d'archives relatant cette affaire sont reproduits dans Nysanbaev, red., Qazaq gazetì, p. 533-544.

52. M. Qojgeldiev, éd., Qazaq ult-azattyq qozghalysy : 4-tom. Qazaq s'ezderì [La rébellion nationale kazakhe. Tome 4, les congrès kazakhs], Almaty : El-šežìre, 2007, p. 47-48.

53. Qojgeldiev, éd., Qazaq ult-azattyq qozghalysy, p. 44-45.

54. Les töre et les qoža n'entrent pas dans la généalogie des tribus kazakhes et occupent un statut privilégié par rapport aux autres Kazakhs. Ils appartiennent à une " classe aristocratique " qualifiée d'Aq sujek [os blanc] qui se distingue des hommes ordinaires qualifiés de Qara sujek [os noir]. Les töre descendraient directement de Gengis Khan. Les qoža, maître de la sphère religieuse, rassemblent des lignages censés descendre des premiers califes et des compagnons du prophète Muhammad. Erofeeva, Rodoslovnye kazahskih hanov i koža XVIII-XIX vv., p. 11-37.

55. Les tölenggìt étaient des lignages de servants de khan, qui se rencontraient dans les trois žüz, et ont formé des lignages voire des tribus selon les sources. Ces lignages s'étaient formés à partir de Kazakhs, appartenant aux différentes tribus, et de représentants d'autres peuples d'Asie centrale, notamment kalmouk et qaraqalpaq, qui avaient été attachés au service d'un lignage töre. F.K. Zobnin, Raby i Tjulenguty v Kazahskoj stepi [Esclaves et tölenggìt dans la steppe kazakhe], Almaty : Altyn kitap, 2007[1902] ; Hamit Madanov, Kiši žüzdìng šežìresì [Généalogie de la žüz cadette], Almaty : Atamura, 1994, p. 164-165.

56. Žarylqap Bejsenbajuly, Qazaq šežìresì [Généalogie des Kazakhs], Almaty : Atamura, 1994, p. 106

57. Allen J. Frank, Muslim religious institutions in imperial Russia : The islamic world of Novouzensk district and the Kazakh Inner Horde, 1780-1910, Leiden : Brill, 2001, p. 93.

58. Saken Sejfullin, Ternistij put [Le chemin épineux], Alma-Ata : Žazušy, 1975, p. 102-104

59. Tomohiko Uyama, «Bahytžan Karataev i alašordyncy : izmenenija vzaimootnošenij [Bahytžan Karataev et les membres d'Alaš orda. L'évolution de leurs relations]», Voprosy arheologii i istorii zapadnogo Kazahstana, $n^{\circ}$ 2, 2010, p. 16-17.

60. Qojgeldiev, éd., Qazaq ult-azattyq qozghalysy : 4-tom. Qazaq s'ezderì, p. 61-64.

61. Tleu Kul'baev, Ajtieva Raušan, Abdrahman Ajtiev - žizn' polnaja mužestva i tragedii [Abdrahman Ajtiev, une vie pleine de bravoure et de tragédie], Almaty : Arys, 2006, p. 27.

62. Ibid., p. 25-26.

63. La Horde de Bukej de la gubernija d'Astrahan' devint, après février 1917, la Steppe kirghize du territoire d'Astrahan'. Puis, lors du $\mathrm{I}^{\mathrm{er}}$ congrès régional des soviets en mai 1918, elle fut rebaptisée oblast de Bukej. 
64. La Horde noghaj fédéra des tribus turkes entre le $\mathrm{XV}^{\mathrm{e}}$ et le $\mathrm{XVI}^{\mathrm{e}}$ siècle et étendit son autorité sur les steppes entre la Volga et l'Ural. La Horde disparut mais l'ethnonyme perdura. Une partie des Noghaj fut ensuite rattachée à la žüz cadette sous le nom de Noghaj-Qazaq, sans être inclus dans aucune des trois unions tribales bajuly, älìmuly ou žetìru. La majorité des Noghaj-Qazaq se trouvait dans la Horde de Bukej.

65. Le recensement de 1917 consulté ne compte que les trois unions tribales, bajuly, älìmuly et žetìru avec respectivement 300 000, 10000 et 10000 individus. Les Noghaj, Qaraqalpaq, tölenggìt et töre ne sont pas mentionnés. Leur nombre devait être pour chacun entre 10000 et 20000 .

66. Eltaj Qaliev, Uälìthan Tanašev žäne Tanaševter äueletì [Valithan Tanašev et la descendance Tanašev], Almaty : KIE, 2009.

67. Qojgeldiev, éd., Qazaq ult-azattyq qozghalysy : 4-tom. Qazaq s'ezderì, p. 192-194.

68. Qojgeldiev, éd., Qazaq ult-azattyq qozghalysy : 4-tom p. 79.

69. S. Mendešev, Moi ličnye vospominanija o mobilizacii kazahskogo naselenija na tylovye raboty v 1916 g. [Mes souvenirs personnels sur la mobilisation de la population kazakhe pour les travaux sur le front en 1916], Trudy obščestva izučenija Kazahstana (t. VIII- vyp. II), Kzyl-Orda, 1926.

70. En 1917, dans l'oblast d'Akmolinsk, la tribu arghyn comptait 390000 personnes, pour 40000 Najman, 70000 Kerej et 40000 Uaq. Dans l'oblast de Semipalatinsk, la répartition était de 420000 Arghyn pour 250000 Najman, 60000 Kerej et 50000 Uaq.

71. L'uezd d'Ust'-Kamenogorsk comprenait presque uniquement des Najman (110 000). L'uezd de Zajsan abritait aussi des lignages kerej, qui ne représentaient que $10 \%$ de la population de l'uezd (10 000 sur 110000$)$.

72. Il s'agit de l'instituteur Biahmet Sarsenov (1885-1921).

73. Les baj, littéralement riches en kazakh, désignaient les notables qui possédaient d'importants troupeaux.

74. Alaš est l'ancêtre mythique des Kazakhs. Reflet de leur unité, il est censé avoir été aussi le cri de guerre des Kazakhs au XVIII ${ }^{\mathrm{e}}$ siècle au moment des difficiles campagnes militaires contre les Djoungars. Au début du $\mathrm{xx}^{\mathrm{e}}$ siècle, certains l'utilisèrent en tant que synonyme de " kazakh » pour nommer le peuple dans son entier. Ce terme entra ainsi progressivement en usage au sein de l'intelligentsia pour symboliser la nation kazakhe.

75. Madijar [M. Dulatov], « Učreditel'noe Sobranie [L’Assemblée constituante] », Qazaq, $n^{\circ}$ 240, 21/08/1917.

76. Le journal Sary-Arqa [la steppe dorée], nom de la région centrale de l'actuel Kazakhstan à cheval sur les oblasts d'Akmolinsk et de Semipalatinsk, fut publié à Semipalatinsk de juin 1917 au début de l'été 1919.

77. L'autonomie turkestanaise, le plus souvent appelée autonomie de Kokand, fut proclamée le 28 novembre 1917 lors du IV ${ }^{e}$ Congrès des musulmans du Turkestan, qui s'était tenu dans la ville de Kokand. M. Tynyšpaev, Kazakh de l'oblast du Semireč'e, en fut le premier président.

78. Un congrès extraordinaire sibérien eut lieu à Tomsk du 6 au 15 décembre 1917. Il rassembla des représentants des organisations démocratiques et révolutionnaires issus d'un spectre politique allant des $\mathrm{SR}$ de gauche aux régionalistes. Les délégués marquèrent leur opposition à la révolution d'Octobre et leur refus de se soumettre au nouveau pouvoir soviétique. Le congrès lança un appel à toutes les organisations sibériennes pour que soit constitué « un pouvoir socialiste pan-sibérien provisoire». Il posa les fondements d'une république autonome sibérienne et nomma un Gouvernement provisoire sibérien sous la présidence de Grigorij Potanin. Après la conférence d'Ufa en septembre 1918, il fusionna avec plusieurs autres gouvernements et s'installa à Omsk. V.V. Žuravlev, « Roždenie Vremennogo sibirskogo pravitel 'stva: iz istorii političeskoj bor'by v lagere kontrrevoljucii [La naissance du Gouvernement provisoire sibérien, une histoire de la lutte politique dans le camp de la contre-révolution]", Graždanskaja vojna na vostoke Rossii. Problemy istorii : Bahrunšinskie čtenija 2001 g. [La guerre 
civile dans l'est de la Russie, Problèmes de l'histoire, lectures de Bahrunšin], Novosibirsk, 2001, p. 26-47.

79. Après la révolution d'octobre 1917, l'ataman Kaledin avait instauré un gouvernement militaire dans la région du Don et fut rejoint par les généraux Alekseev et Kornilov. Leur triumvirat institua l'Union du Sud-Est fin octobre 1917, qui appela toutes les forces opposées au nouveau régime à la rejoindre. Elle fut aussi la base de la première armée blanche, l'Armée des volontaires. Le IV Congrès des musulmans du Turkestan, qui proclama l'autonomie turkestanaise fin novembre 1917, s'était prononcé pour un ralliement à cette union.

80. M. Qojgeldiev, éd., Alaš qozghalysy. Qužattar men materialdar žinaghy. Želtoqsan 1917ž.-Mamyr 1920ž. [La rébellion Alaš. Recueil de documents, décembre 1917-mai 1920], Almaty : Alaš, 2005, p. 144.

81. L'histoire de ce parti présente encore de nombreuses zones d'ombre. L'étude la plus approfondie est celle de Svetlana Smaghulova dans son ouvrage : Kölbaj Tögìsov žäne Üš žüs partijasy [Kol'baj Togusov et le parti Üš žüz], Almaty : Arys, 2009.

82. Le Šura-i-islamija était l'organisation des musulmans du Turkestan créée après la révolution de 1917 par plusieurs personnalités turkestanaises pour représenter la population autochtone.

83. Le plus célèbre Qypšaq ayant rallié le parti Üš žüz fut Hadžimukan Munajtpasov, lutteur mondialement connu, vainqueur de nombreux tournois avant 1914.

84. Leur nombre s'élevait à 20000 dans l'uezd d'Omsk, où les Kerej étaient à égalité avec les Arghyn. Les chiffres étaient de 40000 pour 60000 Arghyn dans l'uezd de Petropavlovsk et de 10000 pour 150000 Arghyn dans l'uezd d'Akmolinsk.

85. Bukejhanov avait été membre du Parti constitutionnel démocrate russe (KD) depuis 1906, mais il quitta ce parti au mois de juillet 1917.

86. « Alastap ajdau kerek [Il faut les évincer]», Sary-Arqa, $n^{\circ} 21,1917$.

87. «Rezoljucija [Résolution]», Revoljucionnaja mysl' [La pensée révolutionnaire], $\mathrm{n}^{\circ} 76$, 22/12/1917, K. Tögìsov [K. Togusov], Šygharmalar žinaghy (recueil de publications), Almaty : Alaš, 2003, p. 208-209.

88. Les bolcheviks étaient tout particulièrement hostiles aux zemstvos, qui furent supprimés par le gouvernement soviétique en 1918.

89. Üš-žüz, n’ 2, 24/12/1917.

90. Cette information est donnée par Džangil'din dans une interview réalisée par A.I. Golubeva (AP RK, 84/6-811/4-a/81).

91. CK partii « Uš-žuz », sans titre, Revoljucionnaja mysl', n 4, 4/01/1918, Tögìsov, Šygharmalar žinaghy, p. 209-210.

92. Le nom de Sejfullin apparaît sur la liste déposée par le parti Üš žüz pour les élections à l'Assemblée constituante, mais l'intéressé n'avait pas été consulté, ce qui était une pratique courante.

93. Nurghali Qulžanov [Nurali Kulžanov], « Alaš avtonomijasy » [L'autonomie Alaš], Üš- žüz, n - 7, 2/03/1918, in Smaghulova, Kölbaj Tögìsov žäne Üš žüz partijasy, p. 218-223.

94. «M. Dulatovtyng Öskemen uezìndegì žaghajdy alašordagha bajandaghan haty (27 mausym 1918) [Rapport de M. Dulatov sur la situation dans l'uezd d'Ust'-Kamenogorsk, 27 juin 1918]", Qojgeldiev, éd., Alaš qozghalysy. Qužattar men materialdar žinaghy. Želtoqsan 1917ž.-Mamyr 1920ž., p. 174-178.

95. La commission d'élaboration de la constitution de la RSFSR devait comprendre un représentant du NKN, avec une voix délibérative, et un représentant de chaque commissariat national avec une voix consultative (protocole $n^{\circ} 4$ (7/04/1918) du NKN, GARF (Gosudarstvennyj arhiv Rossijskoj federacii - Archives d'État de la Fédération de Russie), 1318/17/3).

96. Rapport du NKN au VCIK du 30 avril 1918 (GARF, 1318/1/117/48).

97. Résolution du 2 avril 1918, signée par 71 personnes du parti Üš-žüz, Tögìsov, Šygharmalar žinaghy, p. 205-206. 
98. Semipalatinsk fut prise par les Blancs le 11 juin 1918.

99. Qojgeldiev, éd., Qazaq ult-azattyq qozghalysy : 4-tom. Qazaq s'ezderì, p. 66-67.

100. «Conclusion de la commission de contrôle du comité régional kirghiz au sujet du membre du parti bolchevik A. Kenžin » (23/11/1922), N. Žaghyparov, éd., Alaš qozghalysy-Dviženie Alaš. Säuìr 1920-1928žž [La rébellion Alaš. Avril 1920-1928], Almaty : El-šežìre, 2007, p. 124.

101. Dämetken Sulejmenova, Alašordanyng Batys bölìmìnìng tarihy-ölke tarihyning quramdas bölìgì [La part inaliénable de l'histoire de la branche occidentale d'Alaš orda], Almaty : Arys, 2007.

102. La branche occidentale d'Alaš orda avait ainsi compétence sur les oblasts de Bukej et d'Ural ' sk et sur les uezds d'Irgiz et d'Aktjubinsk de l'oblast de Turgaj.

103. Maqsat Täž-Murat, Ghumar Qaraš : ömìrì men šygharmašylyghy [Gumar Karašev, sa vie et son œuvre], Aktöbe : A-Poligrafija, 2004, p.191-192 ; P. Varlamov, « O 1917 gode v Bukeevskoj orde [Au sujet de l'année 1917 dans la horde de Bukej] », Bol’ševik Kazakstana [le bolchevik du Kazakhstan], n 9-10, 1935, Alma-Ata, p. 118-126.

104. Document $\mathrm{n}^{\circ} 10 \mathrm{du}$ 2/12/1917, Obrazovanie Kazahskoj ASSR (sbornik dokumentov i materialov) [La constitution de la RSSA kazakhe, recueil de documents], Alma-Ata : Izdat. AN KazSSR, 1957, p. 39-40.

105. Ce fut notamment le cas au Turkestan pour les djadides tachkentois ou boukhariotes en 1918. Cf. Hallez, "Turar Ryskulov: the carrier of a Kazakh revolutionary leader during the construction of the new Soviet state, 1917-1926», p. 125-126 ; Gero Fedtke, "Jadids, young Bukharans, communists and the Bukharan revolution: from an ideological debate in the early Soviet Union ", Anke von Kügelgen, Michael Kemper, Allen J. Frank, éds., Muslim culture in Russia and Central Asia from the $18^{\text {th }}$ to the early $20^{\text {th }}$ centuries. vol. 2 : Inter-regional and inter-ethnic relations, Berlin : Klaus Schwarz Verlag, 1998, p. 483-512.

106. [Abdulhamit Žundibaev], «El habarlary» [Nouvelles de la nation], Qazaq, $\mathrm{n}^{\circ} 261$, 23/07/1918, cité par Sejfullin, Ternistij put', p. 162-163.

107. Les villes d'Irgiz, d'Aktjubinsk et de Turgaj résistèrent et furent encerclées par les Blancs pendant toute la guerre civile.

108. La Komuč fut fondée le 8 juin 1918 à Samara. En septembre de la même année, elle organisa une conférence, où furent représentés la plupart des gouvernements blancs, y compris Alaš orda. Un directoire fut formé pour unifier tous ces gouvernements et le Gouvernement sibérien d'Omsk fut reconnu comme pouvoir légitime panrusse. La Komuč avait établi un programme socialiste, mais elle fut vite dépassée par les autres forces politiques plus conservatrices.

109. Izvestija VCIK, 12/05/1918; protocole $\mathrm{n}^{\circ} 18$ de la réunion du collège du Commissariat aux nationalités (29/06/1918), GARF, 1318/17/3

110. Il n'est pas fait mention ici du Turkestan.

111. M. Tungačin, « Dokladnaja zapiska zavedujuščego kirgizkim otdelom pri Narkomnace v Narodnyj komissariat po delam nacional'nostej o položenii v Bukeevskoj stepi [Rapport du bureau kirghiz du NKN au Commissariat du peuple aux nationalités sur la situation dans la steppe de Bukej] », 8/09/1918, Innostrannaja voennaja intervencija i graždanskaja vojna v Srednej Azii i Kazahstane [L'intervention militaire étrangère et la guerre civile en Asie centrale et au Kazakhstan], Alma-Ata : Izdat. AN Kaz.SSR, 1963, t. 1, p. 150-154.

112. Tungačin, « Dokladnaja zapiska zavedujuščego kirgizkim otdelom... », p. 151.

113. Togan Zaki Validi, Vospominanija [Souvenirs], M., 1997, p. 187-195.

114. Žankeldìn [Džangil'din], « Haliq komissarlary sovetìnìng predsedatelì V.I. Leninge radiogramma » [radiogramme adressé à V.I. Lenin, président du Conseil des commissaires du peuple], 25/03/1919 (Taškent), Žankeldìn, Dokumenter men materialdar, p. 115.

115. Il remplaça le Bureau kazakh du NKN, qui devint alors représentation du Comité révolutionnaire kirghiz à Moscou.

116. Zimanov, Dauletova, Ismagulov, Kazahskij revoljucionnij komitet, p. 67-68. 
117. RGASPI (Rossijskij gosudarstvennyj arhiv social'no-politi@eskoj istorii - Archives russes d'État d'histoire sociale et politique), 17/86/129/112.

118. N. Timofeev, « Bor'ba kazakskoj partijnoj organizacii na dva fronta s uklonami v nacional 'nom voprose " [La lutte de l'organisation du parti kazakh sur deux fronts avec les déviations dans la question nationale], Bol'ševik Kazakstana, n 9-10, 1935, p. 75.

119. Lettre de Tungačin du 10/06/1920 à Stalin et Kamenskij, GARF, 1318/1/436/6-7.

120. Lettre de Mjurat au groupe occidental d'Alaš Orda, N. Martynenko, éd., Alaš Orda. Sbornik dokumentov [Alaš orda, recueil de documents], Almaty : Ajkap, 1992[1929], p. 164.

121. Amanžolova, Kazahskij avtonomizm i Rossija, p. 178.

122. Protocole $n^{\circ} 2(22 / 01 / 1920)$, §.1, Protokoly Revoljucionnogo komiteta po upravleniju kazahskim kraem (1919-1920) [Protocoles du comité révolutionnaire pour la gestion du kraj kazakh], Almaty : Nauka, 1993, p. 59-60.

123. Protocole $n^{\circ} 5$ du bureau régional kirghiz du parti communiste (2/06/1920), AP RK, 140/1/4b/18.

124. Les membres en étaient : Pestkovskij et Avdeev, vieux bolchevik, Džangil'din, Ajtiev, Argančeev, Murzagaliev et Aliaskar Alibekov.

125. Protocole $n^{\circ} 5$ du bureau d'organisation kirghiz du parti communiste (7/05/1920), AP RK,140/1/3b/11.

126. D. Lijanov, « Avtonomnaja Kirgizija » [La Kirghizie autonome], Žizn' nacional'nostej, $\mathrm{n}^{\circ} 30$ (87) $1 / 10 / 1920$.

127. «Zajavlenie tovarišča Ahmeta Bajtursynova (v svjazi s perehodom na storonu bol'ševikov) [Déclaration du camarade Ahmet Bajtursunov, en lien avec son passage du côté des bolcheviks] ", Izvestija Kirgizskovo kraja, Orenburg, 15/04/1920.

128. Les frontières revendiquées par le congrès pankazakh intégraient les oblasts de Semipalatinsk, d'Akmolinsk, d'Ural'sk, de Bukej, du Syr-Darya, du Semireč'e et des uezds des oblasts de Samarcande, de Transcaspienne, du Ferghana et de la région de l'Altaj. D.A. Amanžolova, «Kazahskaja avtonomija : ot zamysla nacionalov k samo-opredeleniju po-sovetski » [L'auto-nomie kazakhe : du projet des nationaux à l'autodétermination soviétique], Acta Slavica Iaponica, 21, 2004, Hokkaïdo : « Hokkaïdo University », p. 115-143.

129. Virginia Martin, « Kazakh Chinggisids, land and political power in the nineteenth century : a case study of Syrymbet », Central Asian Survey, 29 (1), 2010, p. 79-102.

130. Bahtygerej Kulmanov décéda du typhus en 1919 et aucun töre ne prit sa place dans l'oblast de Bukej.

\section{RÉSUMÉS}

Cet article présente des parcours individuels et des formes de l'engagement politique dans la société kazakhe entre 1917 et 1920. Il porte sur un pan de l'histoire révolutionnaire qui n'a encore jamais été abordé autrement que par le biais de l'approche idéologique. Le ralliement de Kazakhs au pouvoir soviétique et au parti bolchevik ne peut se comprendre qu'en croisant l'étude du discours politique avec l'influence du contexte général et l'intervention du système tribal. Ce dernier élément est tout particulièrement mis en avant, sans pour autant réduire la vie politique kazakhe à des rapports de force entre tribus. Il apparaît que les Kazakhs devenus soviétiques ou bolcheviks entre 1917 et 1918 appartenaient à des tribus et des clans faibles ou minoritaires et 
qu'ils avaient été mis à l'écart du mouvement national kazakh, dominé par les deux principales tribus. La présente étude s'attache à retracer la constitution de ces groupes hétéroclites. La période est divisée en cinq phases, correspondant à des motivations particulières pour ce ralliement ou, au contraire, pour un rejet du modèle soviétique ou bolchevik.

This article deals with individual biographies and forms of political commitment in Kazakh society during the period 1917-1920. It focuses on a part of the history of the Russian Revolution that has so far been studied only from an ideological point of view. The coming over of Kazakhs to Soviet power or the Bolshevik party can only be understood by crossing the studies of political discourse, the influence of the general context and the presence of a tribal system. The latter is particularly significant for our analysis, but this does not mean that we reduce Kazakh political life to a play for power between tribes. It appears that the Kazakhs who became Soviet or Bolshevik between 1917 and 1918 had in the past been excluded from the Kazakh national movement dominated by the two main tribes and belonged to weaker or minority tribes and clans. This study traces back the constitution of these heterogeneous groups. The period is divided into five stages corresponding to specific motivations for the rallying to or rejection of the Soviet or Bolshevik model.

\section{AUTEUR}

\section{XAVIER HALLEZ}

CETOBAC, EHESS, Paris, xnjhallez@yahoo.com 